\title{
Intrinsically conducting polymers and their combinations with redox-active molecules for rechargeable battery electrodes: an update
}

\author{
Veniamin V. Kondratiev ${ }^{1} \cdot$ Rudolf Holze $^{1,2,3}$
}

Received: 17 November 2020 / Accepted: 19 January 2021 / Published online: 13 February 2021

(c) The Author(s) 2021

\begin{abstract}
Intrinsically conducting polymers and their copolymers and composites with redox-active organic molecules prepared by chemical as well as electrochemical polymerization may yield active masses without additional binder and conducting agents for secondary battery electrodes possibly utilizing the advantageous properties of both constituents are discussed. Beyond these possibilities these polymers have found many applications and functions for various further purposes in secondary batteries, as binders, as protective coatings limiting active material corrosion, unwanted dissolution of active mass ingredients or migration of electrode reaction participants. Selected highlights from this rapidly developing and very diverse field are presented. Possible developments and future directions are outlined.
\end{abstract}

Keywords Intrinsically conducting polymers $\cdot$ Secondary batteries $\cdot$ Redox-active molecules $\cdot$ Electrochemical energy conversion $\cdot$ Electrochemical energy storage

\section{Introduction}

Electronic and electric devices and with growing importance the use of renewable energies need systems for energy storage and conversion. Electrochemical systems are in a prominent position. Most likely they (and specifically lithium ion batteries (Pirnat et al. 2012)) will not provide economically viable large-scale and long-term storage different from frequent advertisements with rather unrealistic claims (e.g., Armand and Tarascon 2008). But they will certainly have an

Dedicated to the memory of Klaus Banert in appreciation of his contributions to interfacial electrochemistry from an organic viewpoint.

Rudolf Holze

rudolf.holze@chemie.tu-chemnitz.de

1 Institute of Chemistry, Saint Petersburg State University, St. Petersburg, Russia 199034

2 AG Elektrochemie, Institut für Chemie, Chemnitz University of Technology, 09107 Chemnitz, Germany

3 State Key Laboratory of Materials-Oriented Chemical Engineering, School of Energy Science and Engineering, Nanjing Tech University, Nanjing 211816, Jiangsu Province, China important role in short-term storage, power quality management and storage at off-grid locations. Their use in mobile and portable applications will definitely grow further. In particular, because of cost considerations and availability of raw materials there are absolutely good reasons to look for organic replacements for the currently used metal-based and inorganic electrode materials. Less environmental problems, in particular, when devices are not properly discarded or recycled and basically unlimited supplies are just a few further arguments.

Very soon after the discovery of their redox behavior (see, e.g., Otero and Cantero 1999; Kita et al. 1986; Matsunaga et al. 1990; Nishio and Furukawa 2011; Mammone 1987) intrinsically conducting polymers ICPs have been proposed as active materials for secondary batteries. Early reviews on their use as active mass or as an additional ingredient improving stability and other performance data are available (Novak et al. 1997; Holze and Wu 2014). Radical polymers (aliphatic and non-aromatic radical-bearing polymers) have been suggested for many applications in energy conversion and storage (Oyaizu and Nishide 2009; Suga et al. 2011), charge transport by self-exchange processes is sufficient even in the absence of charge transport along conjugated segments of a polymer chain to support electrode reactions. Some considerations on tuning the redox potential of 
Fig. 1 Schematic redox reactions of ferrocene and of quinone

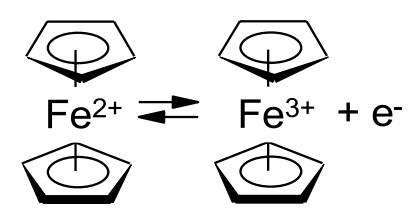<smiles></smiles><smiles></smiles>

Fig. 2 ICP chain with pendant quinone redox moieties (simplified scheme)<smiles>CC(C)(C)Nc1ccc(Nc2cc(O)c(Nc3ccc(Nc4cc(O)c(C(C)(C)C)cc4O)cc3)cc2O)cc1</smiles>

Fig. 3 ICP with redox moieties incorporated in the molecular chain (simplified scheme)

ICP component, a structure as suggested in Fig. 2 seems to be advantageous because the conjugation along the chain necessary for charge movement (i.e., conduction) along the molecular chain is not disturbed, possibly interrupted, by different molecules like quinone units in a polyaniline chain.

Charge storage in battery and in supercapacitor electrode materials can proceed in two initially different ways: By charge separation typical of a capacitor and by electrochemical redox transformation mostly associated with chemical changes, too.

In the former case electrons are moved into/out of the electronically conducting material (commonly called the electrode), to maintain electroneutrality ions compensating for this charge movement are accumulated or dispersed in the adjacent ionically conducting phase. The interaction between the ions and the electrode may be strong enough to suggest chemisorption, weaker interaction may be called physisorption. In both cases electrosorption is operative. 
Sorptive behavior may affect the capacitive performance of the electrochemical interface. Because other factors like ion size, diffusivity, pore size, etc., also affect the performance adsorption is frequently invoked, but hardly examined more closely in the reported literature.

Redox transformations observed with battery electrode materials show widely varying forms. They all share the reversibility of the reaction. A very simple case is the negative lead electrode in the lead acid battery:

$\mathrm{Pb} \rightleftarrows \mathrm{Pb}^{2+}+2 \mathrm{e}^{-}$

An organometallic analogue of this reaction is the ferrocene/ferrocinium electrode according to.

$\mathrm{Fe}(\mathrm{II}) \mathrm{cp}_{2} \rightleftarrows \mathrm{Fe}(\mathrm{III}) \mathrm{cp}_{2}+\mathrm{e}^{-}$.

with the $\mathrm{Fe}(\mathrm{II}) /(\mathrm{III})$ acting as electron source/sink. For charge compensation counterions will move in/out of the respective polymer. Such reaction is not feasible with all metal-free organic electrode materials suggested both for use in the negative and the positive electrode. Instead for metal-ion batteries at the negative electrode a material acting as metal host releasing the metal as cation upon discharge will be required; at the positive electrode the corresponding processes will happen (see Fig. 4).

Charge transfer and storage are associated with changes in bonding from, e.g., double to single bonds, bond rearrangements and redistribution of electrons participating in such bond systems. This is very much different from storage processes in materials like graphene or metal oxides like $\mathrm{LiCoO}_{2}$. Certainly in these cases stoichiometries can be established enabling theoretical charge density calculations. But a fundamental difference-the dominance of covalent bonds in organic materials vs. electrostatic bonding in metal oxides-remains. Graphite at first glance also seems to belong to the class of organic materials because of the covalent bonds between the carbon atoms, but the host's interaction with the lithium or any other metal is more of the non-directional electrostatic or metallic type. Structural aspects like layered architecture in graphite or many other electrode materials $\left(\mathrm{TiS}_{2}\right.$, etc.) or availability of tunnels and other voids are presumably more relevant in more crystalline inorganic materials than in polymeric materials.

Beyond the use of ICPs as active masses their inclusion as binder in electrodes for lithium-ion batteries has been suggested. In the following overview these various uses are addressed and illustrated with examples. Since our earlier review (Holze and Wu 2014) the number of reports on the use of ICPs, their copolymers and their combination with other ingredients beyond redox-active molecules as well as their use as auxiliary materials in various functions have yielded a substantial number of reports. Selective reviews on, e.g., use of PANI (Chen 2019; Gilhotra et al. 2019; Li and Gong , 2020; Luo et al. 2019), polycarbazole (Nayana and Kandasubramanian 2020), PEDOT (Chen and Li , 2020), polypyrrole (Bocchetta et al. 2020) and polyindole (Zhou and Xu 2017) are available. But even more impressive than plain numbers is the width of applications. This makes strict selection of reports included here difficult. Thus, we have decided to focus on representative examples instead of attempting (most likely in vain) to include every report applying most likely arbitrary rules. This will possibly be more helpful in demonstrating the versatility of ICPs and redox-active organic materials for electrodes in secondary batteries thus inspiring and encouraging further research.

Assignment of a report and a described material to any of the classes introduced below were sometimes difficult, possibly arbitrary. Whether an ICP serves as a coating of an active material (a metal oxide, for example) in its various shapes or as an embedding or host material can sometimes be concluded only from the experimental description, unfortunately the authors not always clearly defined function of the various constituents of their electrode materials.

Modeling of ICPs (e.g., PEDOT) in contact with an ionic liquid has been introduced providing a glimpse at

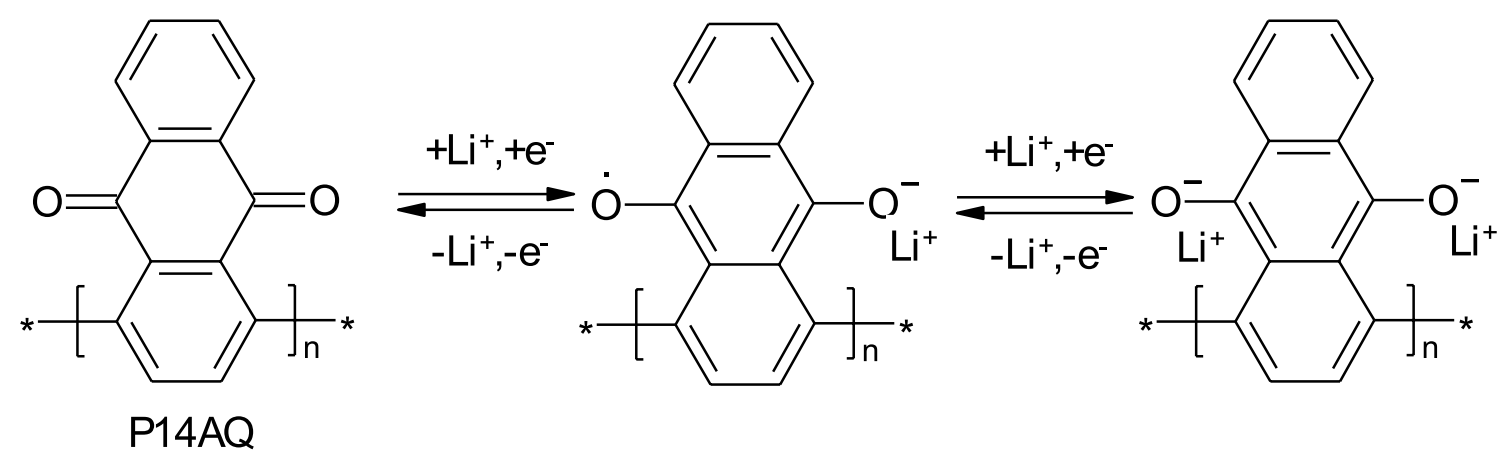

Fig. 4 Redox transformation of a poly(1,4-anthraquinone) during charge/discharge as electrode material in a lithium-ion battery (Song et al. 2015) 
charge distributions and interactions between charged PEDOT and the mobile species (Craig et al. 2020).

Because of possible confusion some terms repeatedly used in the following text are defined following, for some of them a brief definition has been mentioned in passing above.

Intrinsically conducting polymers are macromolecular, polymeric substances with extended conjugated $\pi$-electron systems showing electronic conductivity without added conducting filler materials. Typical examples are conjugated polymers like polyaniline and polyacetylene. Electronic (not ionic) conduction proceeds by electron movement along more or less extended conjugated parts of the polymer chains. Between chains electron hopping becomes operative.

The electrical conductivity of these polymers depends strongly on the degree of oxidation or, as usually stated the degree of doping, which implies the creation of positively (p-doping) or reduction creating negatively charged delocalized states (n-doping) which are compensated by corresponding insertion of counterions. The doping/dedoping processes in the conducting polymers are related to the mixed electronic and ionic transport in the bulk of the material. The electronic conductivity is due to the motion of delocalized electrons or holes along the polymer chains with conjugated bonds, which is accompanied by corresponding motion of charge-compensating ions. These doping processes alter the electrical and optical properties of the intrinsically conducting polymers, and thus, potential control is a prerequisite for obtaining desired properties of polymers.

Some of the numerous ICPs have established themselves as important compounds and components in much different applications, e.g., as antistatic coating, as material in electrolytic capacitors, in printed circuit manufacturing, in organic electronics.

Extrinsically conducting polymers (the term is less common, a frequently used definition does not appear to be established yet) are polymers which become conductive after addition of an electronically conducting agent, and most frequently these materials are just called conducting polymers.

Conducting polymers are macromolecular, polymeric substances showing electronic conductivity only when conducting materials like graphite, acetylene black or metal powders have been mixed into the polymers. Typical examples are conducting rubber or metal-filled polymers. These materials are widely used as flexible contact materials in electronics and in applications where electrostatic charging needs to be handled.

Redox-active polymers (also: redox polymers) are polymers with redox functionalities incorporated either in the polymer chain or as pendant group at the polymer chain (Inzelt 2008). As the main difference from ICPs is charge transport proceeds by exchange reactions between the localized redox groups. Redox polymers are applied in sensors, medicine and energy technology (Casado and Mecerreyes 2020).

Successful application of an ICP in whatever function critically depends on the stability of the ICP itself, but even more on the stability of the device. Thus, particular attention is paid to stability aspects in the following overview. When stated in the original reports we have included information about number of recorded charge/discharge cycles, capacity retention after a number of cycles and further details helpful in assessing stability of a material or a device. This property is frequently not considered adequately for a practical use: A battery stable for 50 cycles or less can hardly be called a promising option despite highly optimistic claims of an author. Unfortunately, reports are sometimes a bit diffuse regarding the distinction between stability of an electrode and of a complete cell. When cell data are definitely reported this is explicitly stated below.

The energy storage performance of an electrochemical device critically depends on the amounts of charge stored in both electrodes and the cell voltage observed between these electrodes. Energy storage with respect to a single electrode does not make sense, it is impossible. Why and how it is frequently reported nevertheless has been discussed elsewhere (Ge et al. 2020, 2021; Holze and Wu 2021). Storage capabilities in terms of theoretical and/or theoretical gravimetric or volumetric charge densities (sometimes slightly imprecisely called capacities (see Dubal et al. 2015, 2016a, b), in units of A $\cdot \mathrm{s} \cdot \mathrm{g}^{-1}$ ) can be calculated. In case of a battery electrode (material) with a well-established electrode reaction equation calculation of a theoretical value of a gravimetric charge density assuming complete conversion of the reactants and exact knowledge of the electrode reaction (Beck and Euler 1984) is no problem. Reporting of volumetric data will be more difficult because reliable and exact knowledge or even more determination of the volume of a more or less porous electrode is a non-trivial task. Practical values are more complicated because they depend on experimental parameters. The electrode potential limits where charge/discharge have been started and stopped are obviously of major importance, because of the influence of charge/discharge current on electrode potential (overpotentials (Vetter 1967)), values, will be smaller when reported at higher currents. Accordingly, comparisons between different reports and materials may be rather imprecise. Matters are even more complicated with supercapacitor electrode materials. For double-layer storage materials there are no electrode reaction equations, accordingly this point of reference is missing. Because the amount of charge stored with these materials depends on the change of electrode potential a value of charge specified with respect to this change and the mass (in units of A s V${ }^{-1} \mathrm{~g}^{-1}$ or F $\mathrm{g}^{-1}$ ) can be provided based on experimental data. Theoretical storage capabilities (sometimes also called capacitances, see (Dubal et al. 2015, 2016a, b)) are difficult 
to establish (Ge et al. 2021). For supercapacitor electrode materials utilizing redox reactions this problems becomes even more intricate. The availability of a redox reaction equation (even when incorrectly displayed as frequently observed) suggests a calculation as simple as done for a battery electrode material sometimes conveniently neglecting the rather different electrochemical response of the material (pseudocapacitive). This matter appears to be beyond the scope of the present report, but the noticeable merger of supercapacitor and battery electrode materials with some materials discussed below showing up also in supercapacitor electrodes (Holze 2020) suggests a short mentioning. In any case in the present report storage data are not provided. Although the dominant aim of many reported studies seems to be a value as high as possible incomplete reporting of experimental parameters and frequently lack of comparability as discussed elsewhere (Ge et al. 2020) leave such numbers with rather limited practical value.

\section{Active masses}

Following ICPs, further polymers, copolymers and further combinations are briefly presented starting with materials employing in addition to an ICP a redox-active moiety.

\section{Quinones in secondary batteries}

2-Aminoanthraquinone as redox-active storage material was kept in place by a combination of polyacrylic acid and PANI (Tong et al. 2020). The latter provided electronic conductivity, the former condensed with the amino-compound keeping the otherwise soluble molecule in place. Two thousand cycles could be achieved.

The lithium salt of poly(2,5-dihydroxy-p-benzoquinonyl sulfide) (60\%wt) mixed with acetylene black (30\%wt.) and PTFE (10 wt.) as binder was used as the positive electrode in a lithium-ion battery by Song et al. (2014). At an average polymerization degree of 7 solubility of the organic material in the electrolyte solution was irrelevant, further advantages of the electrode mixture resulted in a capacity retention of $90 \%$ after 1500 cycles at a Coulomb efficiency of around $100 \%$. Poly (2,5-dihydroxy-1,4-benzoquinone-3,6-methylene) as a positive electrode material for lithium-ion batteries has been proposed (Le Gall et al. 2003), it kept $90 \%$ of its initial storage capability after 100 cycles.

A quinone-formaldehyde polymer was synthesized by Pirnat et al. and studied as an electrode mass for lithium-ion batteries (Pirnat et al. 2016). Poly(5-amino-1,4-dihydroxy anthraquinone) (see Fig. 5) has been proposed as positive electrode material for lithium-ion batteries by Zhao et al. (2013)

The PANI-related molecular structure was invoked as supporting electronic conductivity of the material,

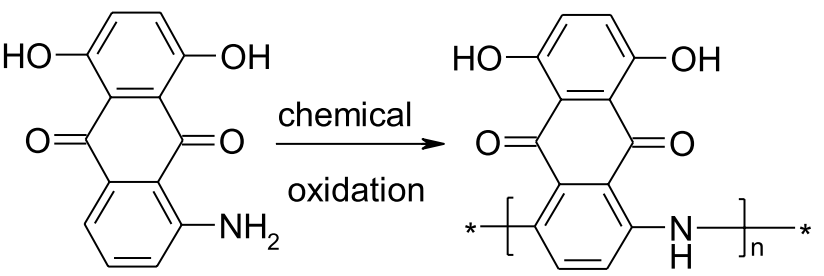

Fig. 5 Reaction scheme of the polymerization of 5-amino-1,4-dihydroxy anthraquinone into poly(5-amino-1,4-dihydroxy anthraquinone) (Zhao et al. 2013)

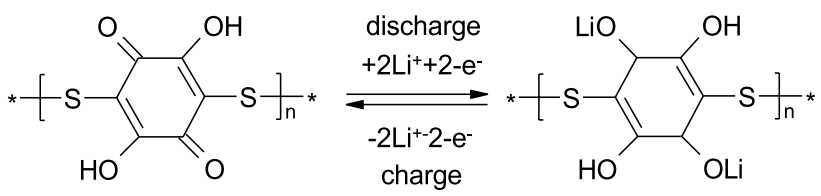

Fig. 6 Poly(2,5-dihydroxyl-1,4-benzoquinonyl sulfide)

nevertheless the electrode material contained $40 \%$ wt. acetylene black and 19\%wt. binder (PTFE).

Rapid performance deterioration of polyquinone as a positive electrode material in a lithium-ion battery by electrochemical lithiation has been reported by Ignatova et al. (2017). In a theoretical study of poly(2,5-diaza-1,4-benzoquinone) Shestakov estimated promising storage capability (Shestakov et al. 2018). Polyanthraquinone has been prepared by a simple polycondensation reaction with poly $(1,5-$ anthraquinone) being particularly stable as positive electrode in a lithium-ion battery (Song et al. 2015).

Poly(2,5-dihydroxyl-1,4-benzoquinonyl sulfide) (see Fig. 6) in a composite with CNTs has been used as positive electrode in a flexible pouch lithium-ion battery with a negative lithium electrode employing PANI-coated CNTs as lithium metal hosts (Zhang et al. 2019a).

After 90 cycles about $71 \%$ of the initial cell capacitance were retained.

Sterby et al. (2017) prepared a PEDOT from EDOT monomer units functionalized with p-benzoquinone using various linker groups. The material was tested in aqueous secondary batteries. Fast redox conversion of the quinone unit was found in an electrode potential region where the PEDOT was electronically conducting. This aspect is of particular importance when considering preparation of an active mass without added conducting carbon.

Inclusion of the catechol moiety increased the storage capability threefold. PEDOT with pyridine and quinone groups in the sidechains (see Fig. 7) with the pyridine moiety acting as proton trap keeping the protons released during oxidation of the hydroxyl group at the hydroquinone substituent thus making this electrode material versatile in nonaqueous electrolyte solutions ( $\AA$ kerlund et al. 2019). 
Fig. 7 Substituted PEDOT with pyridine and quinone groups in the sidechains (Ákerlund et al. 2019)
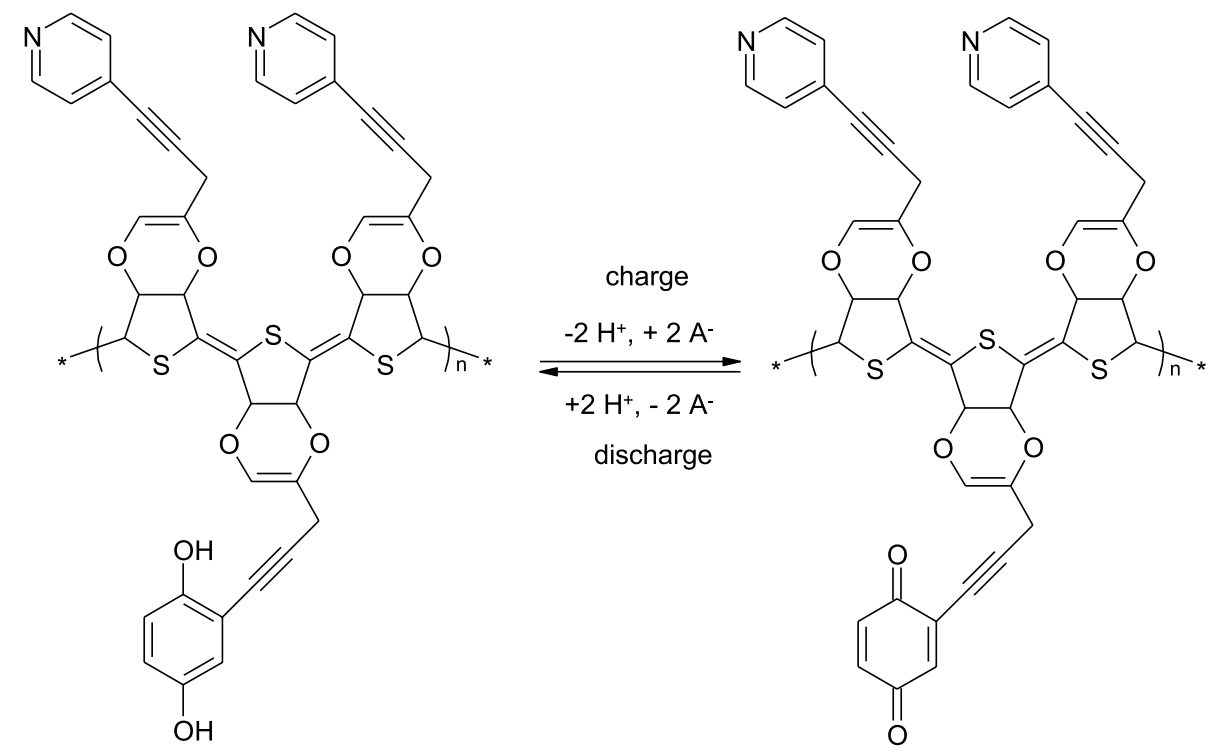

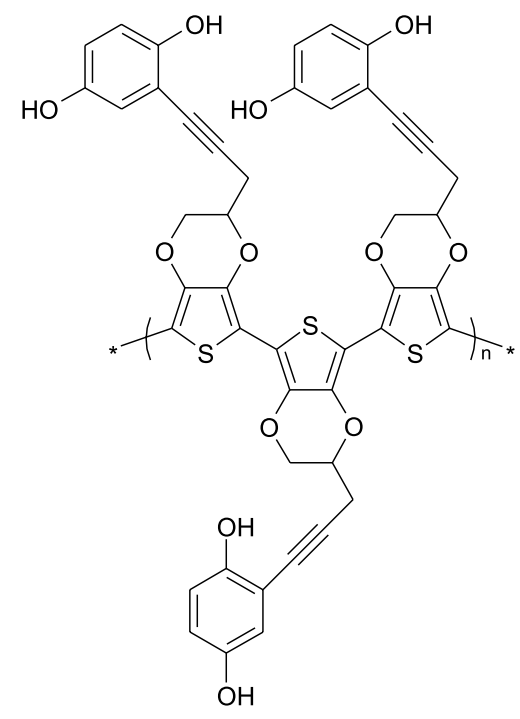

Fig. 8 Substituted PEDOT with quinone groups in the sidechain (Oka et al. 2019)

A quinone-substituted PEDOT (Fig. 8) has been suggested as positive electrode material for lithium-ion batteries (Oka et al. 2019). The redox transition of the pendant quinone happens in the electrode potential range wherein PEDOT is in its highly conducting state, this supports utilization of its storage capability. High rate capability of the material with a water-in-salt electrolyte has been observed.

A polymer with a polythiophene backbone and diethyl terephthalate pendant groups has been proposed as negative electrode material for lithium-ion batteries (Yang 2016). The high rate capability is attributed to the open (porous) morphology and the fast electron transport along the PTh backbone. Designation of the material as redox polymer instead of intrinsically conducting polymer (Inzelt 2008) is slightly confusing.

Electrode kinetics of poly(pyrrol-3-ylhydroquinone) suggested as electrode mass for secondary batteries have been examined (Karlsson et al. 2014). With very thin films kinetics were limited by the quinone redox process.

Cross-conjugated oligomeric quinones combined with CNTs have been suggested as cathode material for lithiumion batteries with a two-step lithiation process as charge storage reaction depicted in Fig. 9 Jing et al. (2017).

Ninety-six percent of the initial storage capability were still present after 250 cycles, this suggests effective suppression of active mass dissolution being a common problem of organic electrode materials in lithium-ion batteries with organic solvents in the electrolyte solution.

The lithium salt of tetrahydroxybenzoquinone has been proposed as a positive electrode material for a lithiumion battery (Chen et al. 2009). Tetrahydro-hexaquinone has been examined as an electrode material by Zou et al. (2014). A quinone derivative of calyx[4] arene combined with carbon black used as the positive electrode in a lithium-ion battery showed improved stability and kinetics when comparing materials obtained by chemical and electrochemical grafting of the active moieties ion a carbon support (Pirnat et al. 2012). Success of electrochemical grafting depended more on surface properties of the used carbon substrate. Dibenzo[b,i]thianthrene-5,7,12,14tetraone has been suggested as a particularly stable positive electrode material providing large storage capability (Ma et al. 2016).

Sulfonated substituted anthraquinone has been examined as positive electrode material in a potassium-ion battery by Zhao et al. (2018). After 100 cycles no capacity loss was noticed. 
Fig. 9 Two-step lithiation/delithiation process of poly(benzo[1,2-b:4,5-b'] dithiophene-4,8-dione-2,6-diyl)<smiles>CC(C)(C)C1=CC2=C(C1)C(=O)c1cc(C(C)(C)C#C[18F])sc1C2=O</smiles><smiles>CC1=CC2=C(C1)C(O)C1C=C(C)SC1C2O</smiles>

Fig. 11 Poly(3,4-dihydroxystyrene)<smiles>CC(C)(C)C(C)(C)c1ccc(O)c(O)c1</smiles>

Fig. 11) has been prepared and combined with PEDOT into a composite for use as a positive electrode material in a lithium-ion battery (Lukyanov et al. 2019).

PHS alone shows moderate performance. When combined with PEDOT the rate performance was improved considerably suggesting a catalytic effect of PEDOT, after 50 cycles about $65 \%$ of the initial capacitance were left.

The glass fiber separator in a lithium-ion sulfur battery was modified with potassium-modified graphene, PANI and poly-1,5-diaminoanthraquinone for enhanced suppression of polysulfide movement (Kiai and Kizil 2019). The noticed suppression was assigned to a "strong binding energy for the adsorption of polysulfides."

Trapping of quinones inside a zeolite-templated carbon (ZTC) has been suggested as another option to suppress their dissolution and associated electrode capacitance loss (Nueangnoraj et al. 2016). When two different quinones, e.g., anthraquinone and tetrachlorohydroquinone, with different redox potentials were used, an organic proton battery could be assembled with $29 \%$ capacitance loss after 500 cycles.

Somewhat beyond the scope of this update is the use of 3,4,9,10-perylene-tetracarboxylicacid-dianhydride (PTCDA) as positive electrode material for a sodium-ion battery with a capacity retention of $66.1 \%$ after 200 cycles (Chen et al. 2015). 




Fig. 12: 6-(2-amino-phenol-9H-yl)-hexyl ferrocenecarboxylate

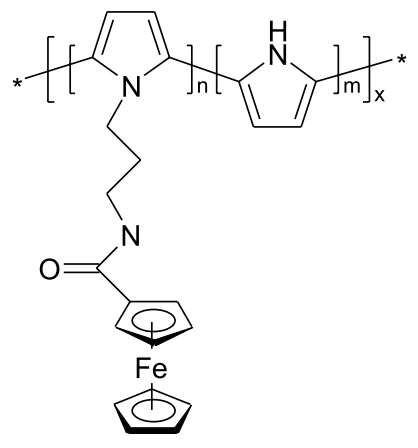

Fig. 13 Copolymer of pyrrol and [(ferrocene) amidopropyl]pyrrole

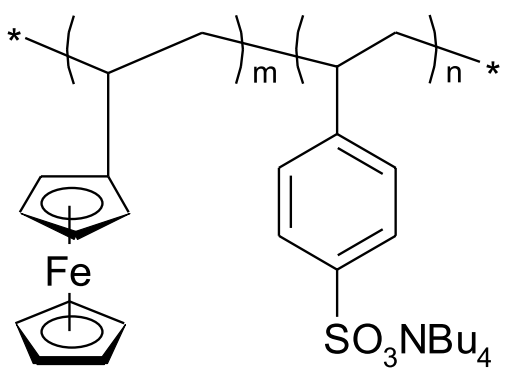

Fig. 14 Poly(styrenesulfonate-co-vinylferrocene)

\section{Ferrocenes in secondary batteries}

Su et al. (2015) reported on a ferrocene-substituted aniline (6-(2-amino-phenol-9H-yl)-hexyl ferrocenecarboxylate) (Fig. 12) that has been synthesized and polymerized by chemical oxidation. For comparison a copolymer with aniline and PANI were prepared. The copolymer kept $76.3 \%$ of its initial capacitance after 30 cycles as a positive electrode.

Park et al. (2007) have prepared a copolymer of pyrrol and [(ferrocene) amidopropyl]pyrrole (Fig. 13) yielding a redox-active copolymer with a charge storage capability bigger than the one already provided by the plain PPy.

The observed storage capability was deemed to be unattractive, further research went toward $\mathrm{LiFePO}_{4}$ (LFP) embedded in PPy yielding more than double storage capability. PPy doped with poly(styrenesulfonate-co-vinylferrocene) (see Fig. 14) was proposed as positive electrode in a neutral electrolyte solution zinc battery (Lee et al. 1995).

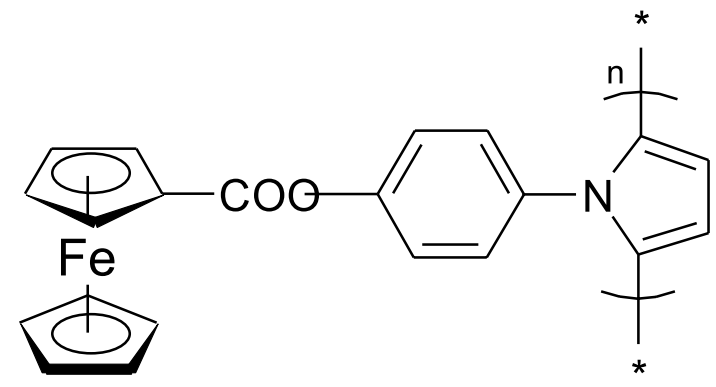

Fig. 15 Poly4-(1H-pyrrol-1-yl) phenyl ferrocenecarboxylate<smiles>[Y]C(C)(C)Nc1cc2c(cc1NC(C)(C)C)NC1C=C[C@@H](NC)C=C1S2</smiles>

Fig. 16 Poly(aniline-co- $N$-methylthionine)

Within 500 cycles no loss of Coulombic efficiency was found.

A homopolymer of 4-(1H-pyrrol-1-yl) phenyl ferrocenecarboxylate (see Fig. 15) has been compared with its copolymer with pyrrol and with PPy for use as positive electrode material in a lithium-ion battery (Su et al. 2013). When compared to plain PPy the copolymer showed a major increase of storage capacity attributed to the ferrocene moiety.

Ferrocene-containing coordination polymers have been suggested as electrode materials for lithium-ion batteries by Strekalova et al. (2019) and Khrizanforov et al. (2019). GO covalently modified with alkyne-terminated ferrocene by a click reaction subsequently mixed with $\mathrm{Mn}_{3} \mathrm{O}_{4}$ and PANI was made into an electrode using additional carbon black and PVDF as a binder on a carbon paper support (Payami et al. 2020) The author did not suggest use of the electrode as positive or negative one. Stability data are a further missing detail.

\section{Miscellaneous copolymers in active masses}

Poly(aniline-co- $N$-methylthionine) (see Fig. 16) has been proposed as active mass for a zinc-ion battery (Chen et al. 2016). The observed gain in storage capability was attributed to the redox-active $N$-methylthionine. $99.4 \%$ of the initial capacity were found after 150 cycles. 
An ester-functionalized poly(aniline-co-fluorene) (see Fig. 17) was suggested as positive electrode for lithium-ion batteries ( $\mathrm{Li}$ et al. 2017) showing a capacity retention of $95.2 \%$ after 50 cycles.

A copolymer of $N$-phenyl- $p$-phenylenediamine and pyrene (see Fig. 18) has been suggested for the positive electrode of a lithium-ion battery (Yao et al. 2019a).

An output voltage of $3.2 \mathrm{~V}$ and $75.2 \%$ capacity retention after 180 cycles were noticed.

The use of PANI as active mass has been hampered by the $\mathrm{pH}$-dependency of the electrochemical activity of this ICP. A copolymer poly(aniline-co-o-aminophenol) provided only minor improvements when compared with plain PANI, stability, in particular, was not noteworthy (Mu 2004). The use of self-doping PANI (sulfonated aniline was used as a comonomer) as positive electrode in an aqueous zinc-PANI battery may solve this problem (Shi et al. 2018). A copolymer of aniline and metanilic acid (3-aminobenzo sulfonic acid) at a 1:1 molar ratio was employed. Similar results were observed with $m$-aminobenzoic acid as comonomer (Rahmanifar et al. 2002). A copolymer of aniline and azure $\mathrm{C}$ was examined as positive electrode material in a quasisolid zinc battery (Li et al. 2019c). More than 1000 cycles were recorded. PEDOT:PSS was used as proton source for $\mathrm{pH}$-management in PANI as positive electrode in a flexible zinc-ion battery keeping about $80 \%$ of its initial capacitance after 1500 cycles (Liu et al. 2019a). A flexible, all-in-one solid-state zinc-ion battery with a composite of PANI and reduced graphene oxide with a solid electrolyte has been described (Zhang et al. 2019b). 94.6\% of the initial capacity were still present after 500 cycles. An assembly of PPycoated nanowires of $\mathrm{MnO}_{2}$ and carbon nanotubes has been examined as positive electrode for a flexible aqueous zincion battery (Zhang et al. 2020c). 87.4\% of the initial storage capability were still present after 1000 cycles. A similar

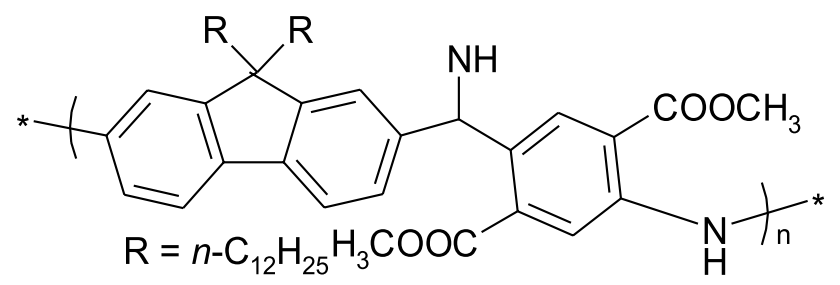

approach with nanorods of $\alpha-\mathrm{MnO}_{2}$ coated with PPy by a "self-polymerization" (using $\mathrm{MnO}_{2}$ as the oxidant) process has been described (Guo et al. 2020). Significant improvement ascribed to suppressed leaching of $\mathrm{Mn}^{2+}$-ions and improved electrode kinetics were stated.

Carbon cloth with deposited PANI on it has been soaked in an aqueous solution of $\left[\mathrm{Fe}(\mathrm{CN})_{6}\right]^{4-}$ yielding a positive electrode material for a zinc-ion battery (Yao et al. 2020). Addition of the hexacyanoferrate improved capacity retention after 1000 cycles from 17 to $71 \%$. Nevertheless reports with plain PANI as active mass for zinc-ion batteries have appeared with rather incomplete details and no data on stability, see, e.g., (Li et al. 2020a).

A copolymer of PANI and a sulfur-containing substituted aniline has been examined as positive electrode in search for a stable lithium-sulfur battery (Dai et al. 2019). After 500 cycles $70.5 \%$ capacity retention were recorded. A similar approach with a highly cross-linked, electronically conducting sulfur-rich copolymer with PANI has been reported (Key et al. 2020). After 450 cycles about $73 \%$ of the initial capacitance were still present.

Copolymers of thiophene and EDOT have been examined as positive electrode material with the 1:1 copolymer being the most stable material (Chang et al. 2005). Copolymers of thiophene and pyrrole at various comonomer ratios have been examined as positive electrode masses for lithium-ion batteries, for comparison PPy prepared at various humidity levels were included (Sanchez De Pinto et al. 1997). The electrodeposition potential had a significant effect on the storage capability of the copolymer, the material prepared at $3.9 \mathrm{~V}$ versus $\mathrm{Li} / \mathrm{Li}^{+}$achieved the highest value.

A copolymer of aniline and $o$-nitroaniline used as positive electrode in a sodium-ion battery showed only minor capacity losses during 50 cycles and a remarkable rate capability (Zhao et al. 2012).

Copolymerization of pyrrole and $N$-(3-hydroxypropyl) pyrrole yielded a positive electrode mass for a lithium-ion battery with higher current and charge storage capability (Chen-Yang et al. 2004). Copolymerization with dopamine resulted in a rather moderate increase in storage capability (Liedel et al. 2018). Agglomeration of PPy negatively affecting its performance as positive electrode in lithium-ion batteries can be suppressed by copolymerization of pyrrole and 4-(1H-pyrrol-1-yl)phenol (see Fig. 19) yielding a material

Fig. 17 Ester-functionalized poly(aniline-co-fluorene)

Fig. 18 Poly $(N$-Phenyl- $p$-phenylenediamine-co-pyrene)

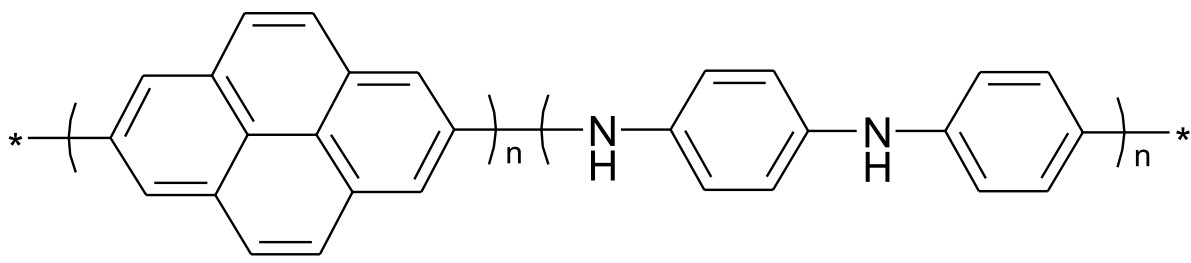




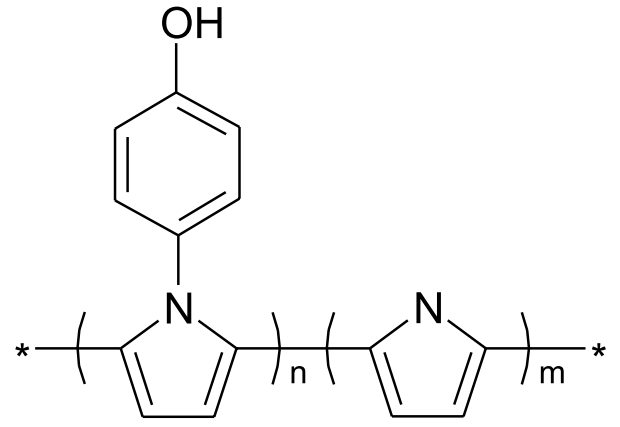

Fig. 19 Poly(pyrrole-co-4-(1H-pyrrol-1-yl)phenol)

with more suitable morphology and tripled storage capability (Su et al. 2012).

PPy, polyazulene and their copolymers have been compared as positive electrode masses for a nonaqueous lithiumion battery (Naoi et al. 1990). Polyazulene showed the highest specific capacitance and rate capability. The latter was attributed to higher diffusivity in polyazulene.

\section{Radicals in active masses}

A copolymer prepared by chemical oxidation of aniline and (4-(6-(2-amino-phenol-9H-yl)hexanoyloxy)-2,2,6,6-tetramethylpiperidin-1-yloxy) (Fig. 20) has been examined in the positive electrode of a lithium-ion battery (Xu et al. 2016). Even the polymer obtained with an optimized comonomer ratio had only $82.7 \%$ of the initial capacitance left after 20 cycles at $31.3 \%$ Coulombic efficiency.

A copolymer of pyrrole and Py-C-TEMPO (see Fig. 21) was used as positive electrode active mass (Xu et al. 2017).

The charge/discharge curves do not show plateaus typical of battery electrode materials but instead are more similar to those obtained with pseudocapacitive materials (Holze 2017) suggesting strong electronic interactions between the redox centers. Significant capacity losses were observed already after 20 cycles.

\section{ICPs and composites in secondary batteries}

Although the rather limited success of early applications of PANI and PPy in secondary batteries seemed to slow

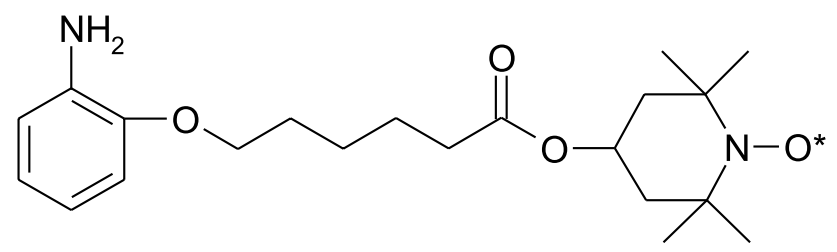

Fig. 20 4-(6-(2-amino-phenol-9H-yl)hexanoyloxy)-2,2,6,6-tetramethylpiperidin-1-yloxy

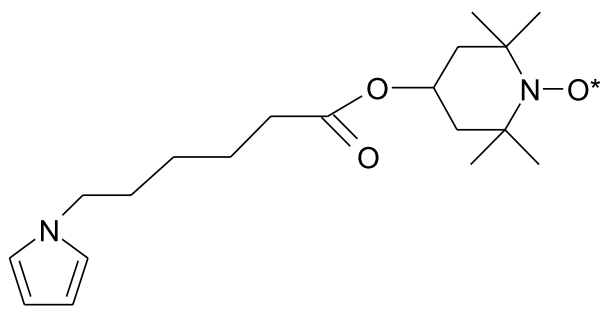

Fig. 21 Py-C-TEMPO

down a bit further development suggestions of ICPs as active masses sometimes with particular attention to specific morphologies and architectures have resulted in a renaissance. Improvement in the perceived structural instability of plain PANI as an electrode material has been achieved by polymerizing aniline in the presence of aramid nanofibers and single-walled carbon nanotubes (Flouda et al. 2020). Nanopillars of PANI deposited on cracked carbon fibers have been suggested for a flexible aqueous zinc-ion battery (Li et al. 2019d). After 1500 cycles the electrode retained 93.2\% of its initial capacity. PANI on carbon paper has been proposed as a negative electrode for a lead acid battery (He et al. 2019). $84.2 \%$ of the initial cell capacity were present after 3000 cycles.

PPy and lithium (tri-(4-carboxyphenyl)amine) have been suggested as positive electrode for a lithium-ion battery $\mathrm{Su}$ et al. 2020). At optimum composition about $10 \%$ capacity loss of the electrode were observed after 100 cycles.

A composite of PANI and 2,5-dimercapto-1,3,4-thiadiazole has been suggested for use in a lithium-ion battery with a gel electrolyte (Sotomoura et al. 1992). Stability data were not reported, the redox reaction used for charge storage was attributed to the organic disulfide, whereas PANI was designated a promoter. Another copolymer of aniline and 1,4-dihydrobenzo[ $[d][1,2]$ dithiin-5-ylamin has been suggested later as potential electrode material (Cho et al. 2001). Practical utilization of the many attractive advantages of sulfur itself as an electrode material in lithium-ion batteries has so far been hampered by several challenges, the solubility of polysulfide intermediates and the associated redox shuttle mechanism is presumably the most prominent. Many attempts to eliminate this problem have been reported. Nano-microspherical and nanotubular PANI-sulfur composites have been suggested with the latter showing higher storage capability and better cycling stability at only $40 \%$ loss after 70 cycles (Wang and Zhang, 2020). The use of PANI as described above will add "dead weight" to the electrode because PANI does not contribute to charge storage. Thus, optimization of PANI coating thickness is welcome as reported by Yao et al. (2019b). At $2 \mathrm{wt} \%$ PANI after 500 cycles $55 \%$ capacity retention were reported. Another option is the use of PPy-coated nanotubes of $\mathrm{MnO}_{2}$ (Du et al. 2019). 
The modified nanotubes accommodated volume changes of the sulfur particles and suppressed polysulfide diffusion; during 700 cycles $0.088 \%$ capacity decay per cycle were observed. Nanosheets of zirconium phosphate coated with PPy served as host for sulfur in a lithium-sulfur battery with the PPy acting as a physical barrier and an electronic conductivity enhancer (Liu et al. 2019b). A mesoporous composite of $\mathrm{TiO}_{2}$ and sulfur with an encapsulation of PPy successfully prevented escape of soluble polysulfides, in addition PPy increased electronic conductivity of the electrode material for a lithium-sulfur battery (Song et al. 2020). $0.103 \%$ capacitance per cycle loss were measured during 300 cycles. Less pronounced effects were reported for composites of $\mathrm{TiO}_{2}$ in PEDOT (Liu et al. 2020d). Microspheres of $\mathrm{Co}_{3} \mathrm{O}_{4}$ embedded in PPy nanotubes served as hosts for sulfur in a lithium-sulfur battery (Wu et al. 2020b). $0.034 \%$ capacitance loss per cycle were observed during 1900 cycles. Channels established by PPy in a sulfur-rich triazine framework contributed to $86.8 \%$ capacity retention after 500 cycles of this positive electrode material (Kim et al. 2020). Further concepts employing ICPs as encapsulating or restraining material to keep sulfur in place and restrict polysulfide movement have been reported (Ahn et al. 2020; Chelladurai et al. 2020; Díez et al. 2020; Gao et al. 2020b, c; Ghosh et al. 2019; Hu et al. 2020; Huang et al. 2020; Kaiser et al. 2019; Lu et al. 2019; Lan et al. 2020; Liu et al. 2019c; Rajkumar et al. 2019; Raulo et al. 2019; Ren et al. 2020b; Song et al. 2019; Tang et al. 2019; Wang et al. 2019a, 2020d, e; Wei et al. 2019b, c, 2020a, b, c; Wu et al. 2019, 2020c; Yang et al. 2020a, b). An overview of the various uses of ICPs in lithium-sulfur batteries is available (Hong et al. 2020).

Growing interest in using selenium instead of sulfur and combining this positive electrode material with other negative ones has resulted in similar considerations for, e.g., a sodium-selenium battery see (Zhang et al. 2019c).

Enhanced storage capability of hyper-protonated PANI nanorods has been observed for an aluminum-ion battery employing $\mathrm{AlCl}_{2}^{+}$as active species (Wang et al. 2020a) Noticeably stability, in particular only $0.003 \%$ capacitance loss per cycle during 8000 cycles was stated ported. Theoretical considerations regarding the interactions between chloroaluminate ions and PANI have been reported (Wang et al. 2020b).

Layered titanate with PANI inserted for increased interlayer spacing and enhanced structural stability as well as higher electronic conductivity has been suggested as negative electrode mass for sodium and potassium-ion batteries (Liao et al. 2020). With sodium ions $99.6 \%$ of the initial capacitance were found after 2500 cycles, and with $\mathrm{K}^{+}$no obvious fading was seen after 2500 cycles. In $\mathrm{V}_{2} \mathrm{O}_{5}$ suggested as positive electrode material for a zinc-ion battery sluggish electrode kinetics (slow zinc-ion intercalation/ deintercalation) could be accelerated by intercalating PANI resulting in increased interlayer spacing (Liu et al. 2020e). A very similar approach has been reported by Chen et al. (2020c); for $\mathrm{V}_{2} \mathrm{O}_{5}$ as positive electrode material in an aqueous zinc-ion battery the same approach and rationale has been reported (Liu et al. 2020f). Nanowires of $\mathrm{V}_{2} \mathrm{O}_{5}$ coated with PPy showed $95 \%$ capacity retention after 1000 cycles in an aqueous zinc-ion battery (Qin et al. 2020). For increased mass loading with $\mathrm{VO}_{2}$ in the positive electrode a $3 \mathrm{D}$ current collector and binder based on carbon fabric and PEDOT has been tested (Ma et al. 2020b). After 2000 cycles 23\% capacity loss for a full cell were recorded. As another option ultrathin nanobelts of $\mathrm{VO}_{2}$ and PEDOT, the exact architecture remains unclear have been suggested with $84.5 \%$ capacity retention of the full battery after 1000 cycles (Liu et al. 2020a, b, c, yd, e, f).

As discussed above the problem of needing an acidic electrolyte (solution) for PANI to work properly and a neutral solution to avoid excessive corrosion of zinc in a secondary battery a polymer of aniline-2,5-disulfonic acid has been suggested (Wang et al. 2020f). With a quasi-solid electrolyte a flexible battery with $80 \%$ capacity retention after 1000 cycles was prepared. Instead of the Ph-dependency of the electrochemical activity of PANI its agglomeration has been invoked as a major cause of poor mass utilization in an aqueous zinc-ion battery (Wang et al. 2019g). Consequently, combination with graphene was proposed resulting in a material with $95.05 \%$ capacity retention after 100 cycles. PPy grown on an aerogel of polyvinyl alcohol served as a flexible positive electrode in an aqueous zinc-ion battery with $76.7 \%$ of the initial storage capability left after 1000 cycles (Li et al. 2019j).

A composite of sulfur and PPy with PSS (the copolymer claimed to be formed in this report is hardly conceivable given the experimental procedure, any experimental evidence is absent) has been suggested as positive electrode for a lithium-sulfur battery (Han et al. 2019). 64\% of the initial capacitance were found after 200 cycles. A copolymer of sulfur and 3-butylthiophene encapsulated with PEDOT:PSS has been examined in a lithium-sulfur battery (Zeng et al. 2017). High stability of the material $(99.947 \%$ capacitance retention per cycle during 500 cycles) was attributed to the high conductivity of the material, physical and chemical confinement of polysulfide electrode reaction intermediates.

In particular, for metal-ion batteries beyond lithium-ion the suitability of ICPs has been examined again, e.g., for an aluminum-ion battery using an ionic liquid as electrolyte (Schoetz et al. 2020). A polymer of $o$-phenylenediamine has been examined as positive electrode for an aqueous zinc-ion battery; it had $66.2 \%$ of its initial capacitance left after 3000 cycles (Zhang et al. 2020a).

Composites of ICPs with metal chalcogenides for use as supercapacitor electrode material have been reviewed 
elsewhere (Fu et al. 2019); given the ongoing merger of the fields of secondary batteries and supercapacitors the reader may inspect this report for further suggestions.

\section{Auxiliary components and functions}

ICPs have been examined as auxiliary materials in secondary batteries in various functions. Strictly speaking ICPs do not act as active masses in these applications, they serve mostly in other functions. Any charge storage is of minor importance if it proceeds at all. Nevertheless these materials act as vital components in battery electrodes meriting their mentioning here. Most frequently, they can be used as coating or as embedding material, obviously these functions may be difficult to distinguish sometimes. Associated functions and advantages of the use of ICPs will be discussed below with selected examples.

A polypyrrole-coated $\mathrm{LiV}_{3} \mathrm{O}_{8}$-nanocomposite has been prepared by Liu et al. (2013) for use as a negative electrode material in a lithium-ion battery with an aqueous electrolyte solution. The basically promising performance of the vanadate was initially compromised by insufficient stability caused by rapid release of vanadium ions into the electrolyte solution. The coating kept these ions in the coated particle (see Fig. 22) and thus enhanced performance stability (see Fig. 23).

A coating with PPy of $\mathrm{V}_{2} \mathrm{O}_{5}$ suggested as positive electrode material in nonaqueous lithium-ion batteries served the same purpose, up to 5000 cycles were recorded (Liang et al. 2020). Core-shell nanobelts of $\mathrm{V}_{2} \mathrm{O}_{5}$ coated with PEDOT have shown remarkable lithium storage capability and even at high rate $(10 \mathrm{C})$ no capacity loss after 500 cycles (Ren et al. 2020a).

Dissolution of $\mathrm{MnO}_{2}$ from an aerogel composite of $\mathrm{MnO}_{2}$ and reduced graphene oxide could be suppressed by coating with PANI ( $82.7 \%$ capacity retention after 600 cycles) (Mao et al. 2020). Reduced electric resistance of the material and enhanced electrode kinetics were also noticed.

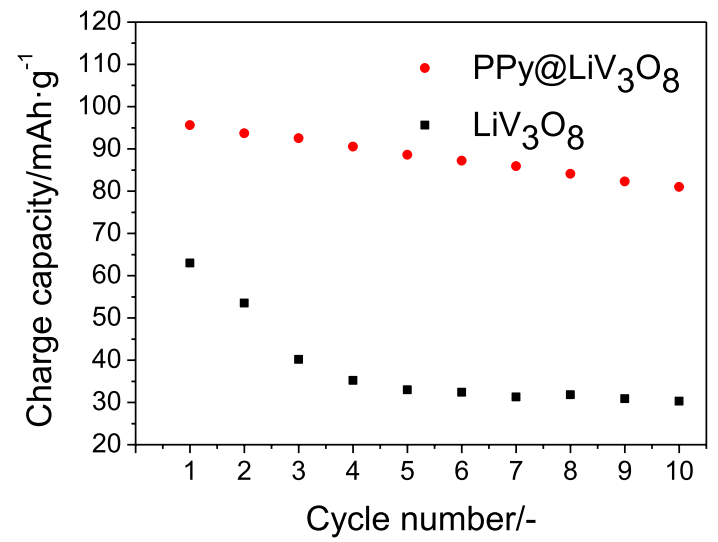

Fig. 23 Cycling stability of coated and uncoated $\mathrm{LiV}_{3} \mathrm{O}_{8}$ in $0.5 \mathrm{M}$ $\mathrm{Li}_{2} \mathrm{SO}_{4}$ aqueous electrolyte solution [based on data in Liu et al. (2013)]

Coating of particles with an ICP (or any other material, also) is frequently associated with the terminology core-shell. The shell—in the present context an ICP—serves again various purposes. As shown above it can keep reactants inside the particle. The function can include mitigation of volume changes otherwise possibly resulting in active mass pulverization. By mechanical and implicitly electronic contact with other coated particles it can also enhance electron transport across the electrode. A typical example is the use of a PEDOT:PSS shell around a $\mathrm{SnO}_{2}$ core ( $\mathrm{Li}$ et al. 2019e). Overall performance improvements, in particular a major stability improvement, were reported. PPy has been used as a coating instead yielding an electrode with $85 \%$ capacity retention after 300 cycles (Wang et al. 2019b). $\mathrm{Li}_{\mathrm{X}} \mathrm{Sn}$ has been examined as negative electrode material with a coating of PPy (Li et al. 2019a). Stable capacity with $86.1 \%$ retention after 300 cycles was reported. Another conversion material considered for use as positive electrode in a sodium-ion battery is $\mathrm{CoS}_{2}$. Like in the previous example volume changes and subsequent electrode pulverization limit the usability of the pristine material. Coating particles of
Fig. 22 Suggested mode of action of PPy coating

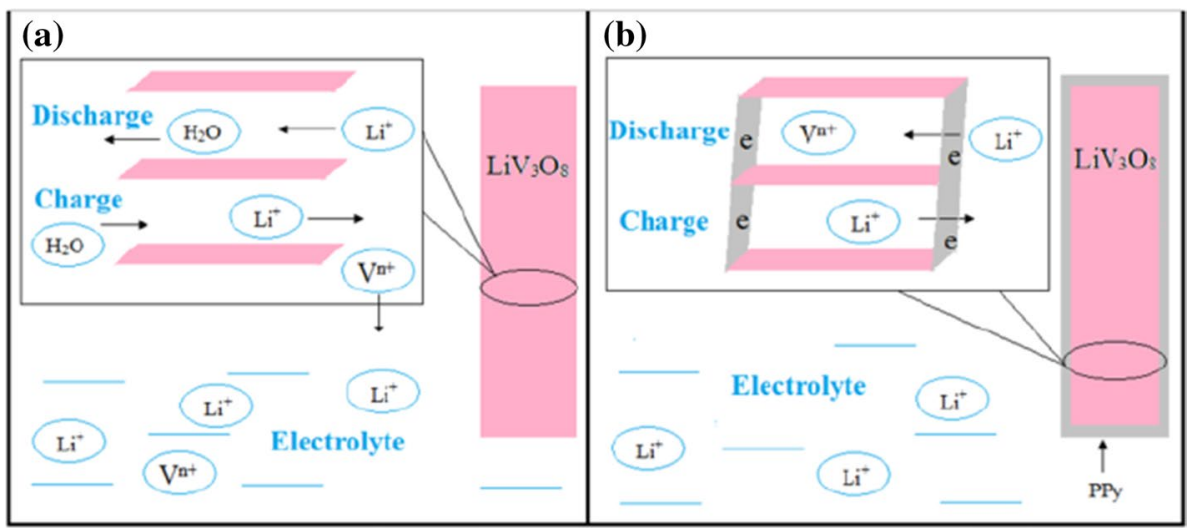


an aerogel of $\mathrm{CoS}_{2}$ and rGO with pyrrole yielding PPy by a vapor-phase process yielded a material with $65.8 \%$ capacity retention after 700 cycles. (Liu et al. 2020c).

Conventionally, carbon coatings are used as a shell to increase the conductivity of electrode materials. A comparison of a carbon coating and polymer coating of $\mathrm{LiV}_{3} \mathrm{O}_{8}$ has shown that the polymer coating provides a greater capacity of the material, but is inferior to carbon in stability (Cao et al. 2015).

Particles of lithium iron silicate, a material with an attractive theoretical charge density, have been encapsulated with PEDOT (Rasool et al. 2020). Some of the numerous drawbacks limiting its application initially could be mitigated. In a similar way the use of $\delta-\mathrm{MnO}_{2}$ as a conversion electrode material for the negative electrode of a lithium-ion battery has been hampered by the inherently low electronic conductivity of $\delta-\mathrm{MnO}_{2}$ and insufficient cycling stability. Coating with PPy has been suggested as an option to remedy both shortfalls (Sui et al. 2020). With films about $50 \mathrm{~nm}$ thick $95 \%$ of the initial capacitance were observed after 120 cycles. The thickness of such coating with PPy by vaporphase polymerization on particles of $\mathrm{FeS}_{2}$ has been examined when the composite was used in the positive electrode of a lithium-ion battery (Wang et al. 2019c). An optimum thickness of $5 \mathrm{~nm}$ was identified. The advantage of a conformal coating of constant thickness using this methodology has also been reported for coating of PPy on $\mathrm{CuO}$ (Zhou et al. 2019). The coating significantly enhanced the available storage capability and cycling stability. Similar results have been reported for this system elsewhere (Feng et al. 2020). Using a wet process a slightly thinner coating of PPy (about $3 \mathrm{~nm}$ ) was identified as an optimum thickness for a $\mathrm{LiNi}_{0.5} \mathrm{Co}_{0.2} \mathrm{Mn}_{0.3} \mathrm{O}_{2}$ (NCM523) electrode in a lithiumion battery (Li et al. 2019f). Coating of this material (also abbreviated as NMC532) with PANI by a vapor-phase process has been investigated thoroughly (Shao et al. 2021). With the best material $84 \%$ of the electrode's initial capacity were still present after 100 cycles. A mixed uniform coating layer of PPy and lithium polyacrylate on particles of $\mathrm{Li}_{1.2} \mathrm{Ni}_{0.2} \mathrm{Mn}_{0.6} \mathrm{O}_{2}$ showing both ionic and electronic conductivity protects the active material against corrosion and other superficial side reactions resulting in $88.5 \%$ capacity retention after 100 cycles (Mu et al. 2019). A combination of PPy and $\mathrm{LiNi}_{1 / 3} \mathrm{Co}_{1 / 3} \mathrm{Mn}_{1 / 3} \mathrm{O}_{2}$ (it remains open whether the ICP served as host or as coating material) resulted in overall performance improvement in a lithium-ion battery (Zhu et al. 2020). Coating of a binary composite of $\mathrm{ZnS}$ and reduced graphene oxide yielded a very stable $(157 \%$ capacity retention after 200 cycles) with remarkable storage capability (Xu et al. 2019). The advantageous properties of the mixed-valence compound $\mathrm{Sb}_{2} \mathrm{WO}_{6}$ are marred by structural collapse during cycling as a battery electrode material. Coating of microspheres of this material with PPy yielded an electrode material showing stable capacity retention during 200 cycles after significant losses in the initial cycles (Yang et al. 2020a). Wrapping of MOF-derived microsheets of $\mathrm{ZnMnO}_{3}$ with PPy yielded a more stable material with improved rate capability (Sun et al. 2020). A coating of PANI (initially called chemisorbed PANI in the report) resulted in increased surface area and optimum porosity of $\mathrm{Co}_{3} \mathrm{O}_{4}$ enabling a storage capability greater by $50 \%$ as compared to the uncoated oxide for use as positive electrode in a supercapacitor/battery hybrid (Izwan Misnon et al. 2020). Manganese hexacyanoferrate as a positive electrode material for sodium-ion batteries shows high theoretical storage capability and working electrode potential, its prospects are dimmed by insufficient cycling stability and poor current capability because of low electronic conductivity. Both flaws can be alleviated with PEDOT. The "reinforcement" reported by Wang et al. (2020c) is apparently a coating of the particles which results in $78.2 \%$ capacity retention after 1000 cycles and further improvements.

Boosting of the sodium storage in Prussian blue nanocubes and its analogues has been observed (Kim et al. 2019a). During 100 cycles no capacity loss was observed. Further considerations of the function of coatings have been discussed elsewhere (Kim et al. 2019b). $\mathrm{MoS}_{2}$ as an attractive material for lithium (Gao et al. 2020a) and sodium-ion storage in the negative electrode suffers from poor electronic conductivity and volume changes during charge/discharge. Using hollow nitrogen-doped carbon spheres as host for $\mathrm{MoS}_{2}$ and a coating with PPy a material with a fairly stable sodium storage capability after serious losses in the initial cycles was prepared (Wang et al. 2019d). $\mathrm{MoO}_{3}$ particles employed as hosts for $\mathrm{Al}^{3+}$-ions in an aluminum-ion battery have been coated with PPy (Wang et al. 2019e). 83.2\% capacity retention after 100 cycles were reported.

Lithium-rich manganese compounds attractive as positive electrodes for lithium-ion batteries are hampered by poor rate performance, lacking stability and voltage decay. In case of $\mathrm{Li}_{1.2} \mathrm{Mn}_{0.54} \mathrm{Ni}_{0.13} \mathrm{Co}_{0.13} \mathrm{O}_{2}$ a mixed coating of PANI and $\mathrm{Li}_{1.4} \mathrm{Al}_{0.4} \mathrm{Ti}_{1.6}\left(\mathrm{PO}_{4}\right)_{3}$ suppressed active mass dissolution and improved rate performance showing $79 \%$ capacity retention after 200 cycles (Lai et al. 2019). A similar approach has been studied for nickel-rich $\mathrm{LiNi}_{0.8} \mathrm{Co}_{0.1} \mathrm{Mn}_{0.1} \mathrm{O}_{2}$ with a coating of PPy and $\mathrm{LiAlO}_{2}$ (Ma et al. 2020a). After 100 cycles (presumably the meaning of "loop") $92.8 \%$ of the initial electrode capacitance was left.

Another coating on a much larger scale is the encapsulation of the lithium metal electrode used as negative electrode securing dendrite-free metal deposition upon charging. A mesoporous PPy-graphene oxide heterostructure has been proposed enabling 1000 stable charge/discharge cycles with more than $90 \%$ capacitance retention after 450 cycles (Shi et al. 2020). 
The low electronic conductivity of $\mathrm{MnO}_{\mathrm{x}}$ has hampered its use as a positive electrode material in zinc-ion batteries. A nanocomposite with PPy prepared in a simple onepot reaction has shown good rate performance and stability (Li et al. 2020b).

Most simply a composite electrode material can be obtained by simply pressing $\mathrm{LiMn}_{2} \mathrm{O}_{4}$ and PPy powder without using any binder (Kuwabata et al. 1999). It was shown that PPy works well as a conducting matrix, improving electrochemical performance of the composite cathode material $\mathrm{LiMn}_{2} \mathrm{O}_{4} / \mathrm{PPy}$.

ICPs can be used as the (only) binder, completely replacing traditional polymer like PVDF.

With increased amounts of ICPs electrodes without added carbon can be prepared, for example for $\mathrm{LiFePO}_{4}$ with 17-20 wt\% of PEDOT (Cíntora-Juárez et al. 2014). Various preparation methods were tried, clear distinctions between coating of active material particles, mixing with ICP powder (blending) or electropolymerization of the ICP in the presence of active material particles are hard to identify. This difficulty will possibly cause uncertainties regarding assignment of a particular material in the following overview.

By emulsion polymerization a copolymer of conductive polypyrrole and poly(acrylonitrile/butyl acrylate) was prepared for use as a binder in the positive electrode in a lithium-ion battery with $\mathrm{Li}_{4} \mathrm{Ti}_{5} \mathrm{O}_{12}$ as active mass (Qi et al. 2020). Improved rate capability was attributed to the conducting PPy-segments whereas the enhanced stability was assumed to be due to the adhesive properties of the second polymer, in particular, when the ratio of the comonomers was at the optimum.

PEDOT has been used as a conductivity-enhancing coating on $\mathrm{LiFePO}_{4}$ by Lepage et al. (2011) for use as positive electrode active mass in lithium-ion batteries. The coating with a thickness of a few nanometers was applied with a soft chemistry procedure. The oxidative capability of $\mathrm{Li}_{(1-\mathrm{x})} \mathrm{FePO}_{4}$ was utilized to polymerize chemically EDOT yielding PEDOT-coated particles as schematically illustrated in Fig. 24.

No additional carbon was needed to achieve the electronic conductivity of the active mass, as a binder PVDF was used.

Similar results were reported using PEDOT:PSS (see Fig. 25) coated from its solution (Dinh et al. 2013). Coating with PEDOT:PSS from an aqueous dispersion has been suggested as another option (Raj and Sil 2019) (while conveniently ignoring the report by Lepage et al. (2011)). Various modes of blending/mixing $\mathrm{LiFePO}_{4}$ with PEDOT have been evaluated, stability data were not provided (Ozerova et al. 2020). Uniform coating of $\mathrm{LiFePO}_{4}$ with PPy (as already mentioned above) of about $5 \mathrm{~nm}$ thickness yielded a positive lithium-ion battery material with promising low-temperature performance and rate capability, both presumably due to the added PPy coating, and a capacity stable for at least 50 cycles (Gao et al. 2019).

At this point it is worth noting that of all examined ICPs PEDOT:PSS has probably the brightest perspective for application in battery materials. In many reports it is simply blended as its dispersion (which is stable and commercially available) into a standard-composition electrode containing added carbon and one of the conventional binders. Beyond the positive effects of the ICP there is almost no change in the process of preparation of the electrode; in addition good mechanical stability provided by conventional binders.

Cíntora-Juárez et al. (2015) examined two compositions of $\mathrm{LiFePO}_{4}$ electrodes containing PEDOT:PSS in different ratios: LFP/C/PVDF/PEDOT:PSS 79/7/7/7 and $84 / 8 / 7 / 1$. Since PEDOT:PSS is not very conductive (about $1 \mathrm{~S} \mathrm{~cm}^{-1}$ ) added ethylene glycol and dimethyl sulfoxide, which increase the conductivity of the polymer, were tried. In both cases a significant improvement in electrochemical performance was observed compared to electrodes prepared with PVDF only.

Using PEDOT:PSS as a binder can reduce the content of inactive battery components as proposed by Das et al. (2015) to use compositions without added carbon with

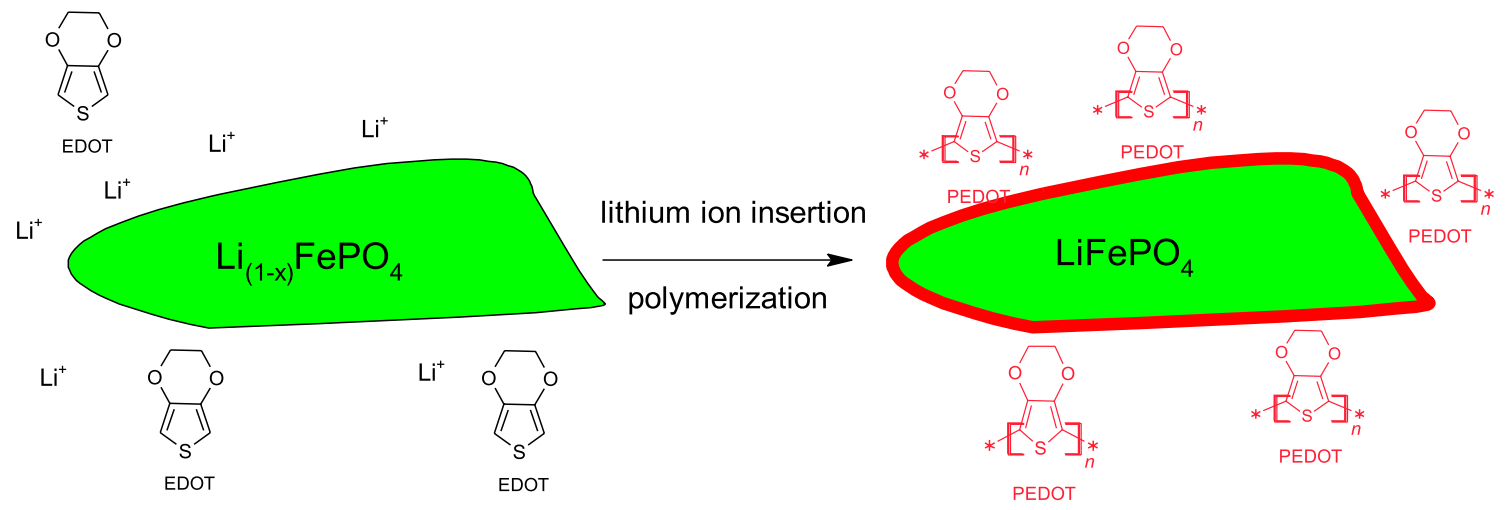

Fig. 24 Formation scheme for core-shell structures $\mathrm{LiFePO}_{4} / \mathrm{PEDOT}$ 
Fig. 25 PEDOT:PSS

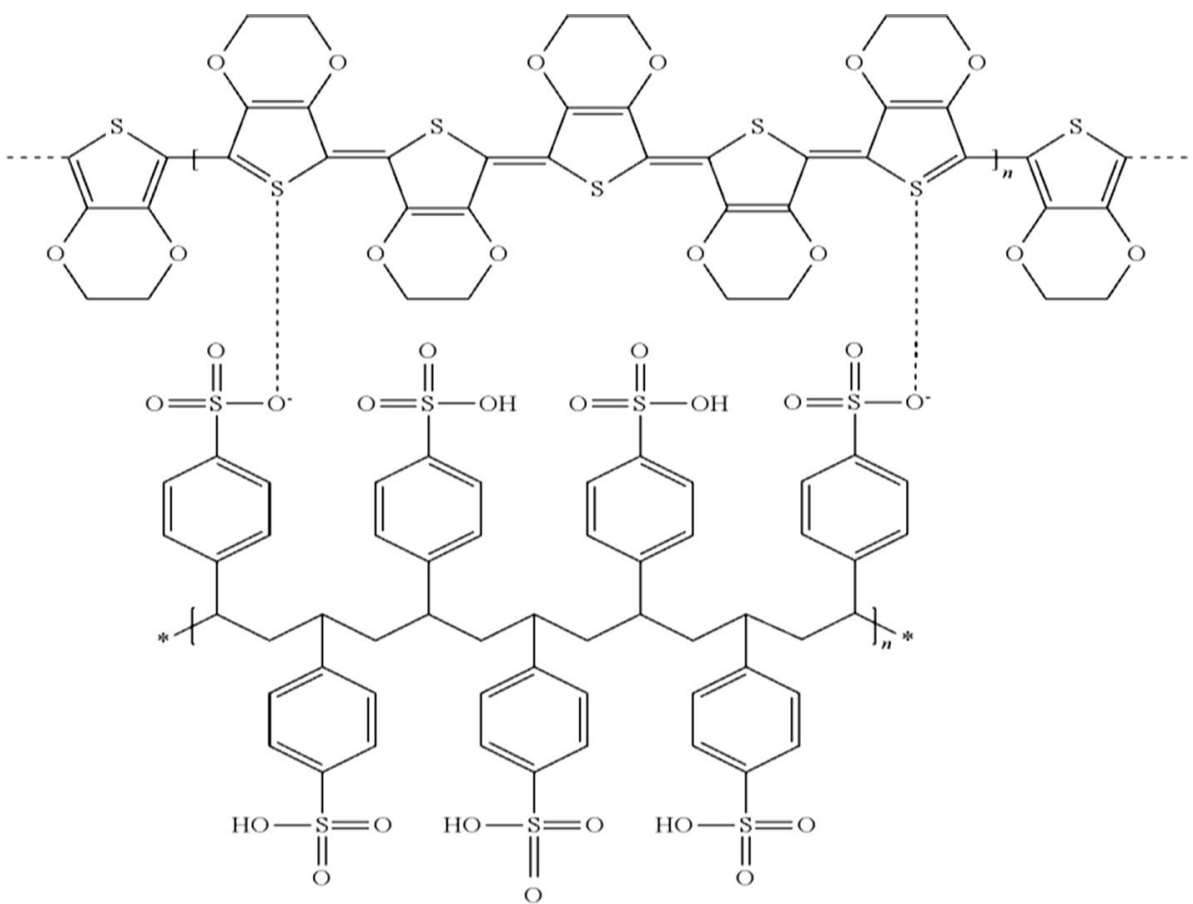

increased mass of LFP 92 and $94 \mathrm{wt} \%$. This type of dispersion can be easily modified for use in printing technologies. PEDOT:PSS and LFP ink was used to print lithium-ion battery cathodes showing improved performance compared to electrodes printed with carbon additives and PVDF (Syrový et al. 2016).

Potentially, replacing conventional binder with PEDOT:PSS allows an increase of the mass fraction of the active component up to $99.5 \%$, thus reaching extremely high capacity values (Kim et al. 2014). However, the decrease in the mass fraction of the binder inevitably worsens the mechanical properties of electrode materials, which is exacerbated by the relatively moderate adhesion of PEDOT:PSS, as well as by by-products of phase separation of dispersion when drying out.

An alternative approach using a redox copolymer poly(4-((10-(12-dodecyl phenoxazine) vinylpyridinium)co-4-vinylpyridine) (Fig. 26) as binder has been suggested (Wang et al. 2009). Charge is shuttled between the current collector and particles of $\mathrm{LiFePO}_{4}$ via the phenoxazine units.

A copolymer of polyaniline and poly(ethylene glycol) has been suggested as a coating for $\mathrm{LiFePO}_{4}$ (Dong et al. 2014). The electrodes prepared with added acetylene black and PVDF as a binder kept $95.7 \%$ of their initial capacitance after 100 cycles. This copolymer has also been coated on $\mathrm{LiNi}_{0.6} \mathrm{Co}_{0.1} \mathrm{Mn}_{0.3} \mathrm{O}_{2}$ for the positive electrode in a lithiumion battery (Yoo et al. 2017). Enhanced electrode kinetics and improved stability (3\% capacitance loss during 50 cycles) were attributed to the coating. The use of ICPs as an effective means to remedy poor electronic conductivity and

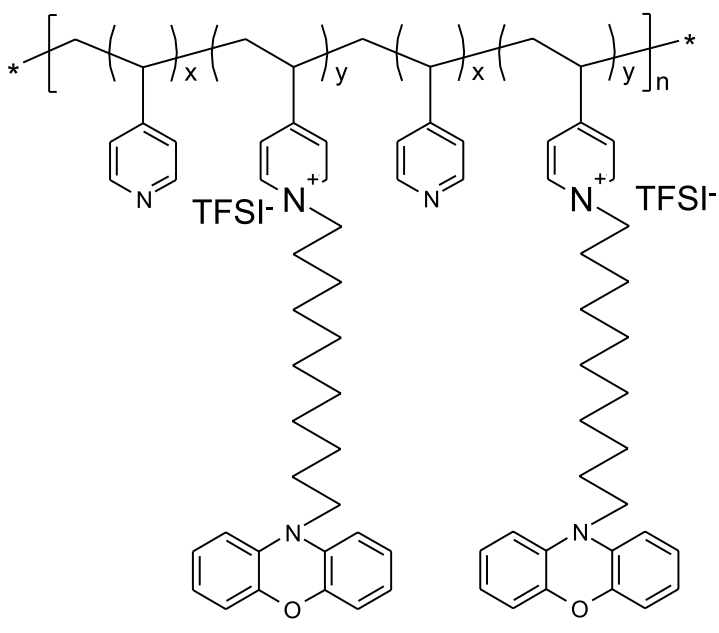

TFSI-: bis(trifluoromethanesulfonyl) imide

Fig. 26 Poly(4-((10-(12-dodecyl phenoxazine)vinylpyridinium)-co4-vinylpyridine)

volume changes of electrode materials has been extended to, e.g., $\mathrm{ZnFe}_{2} \mathrm{O}_{4}$ (Hou et al. 2019). Nanowires encapsulated with PPy showed a capacity almost stable over more than 200 cycles after some initial fluctuation assigned to some activation process. Spherical particles of $\mathrm{ZnFe}_{2} \mathrm{O}_{4}$ coated with PPy for use as positive electrode material (Jiang et al. 2019); the capacity remained practically unchanged after 500 cycles. Coating of nanosheets of $\mathrm{ZnFe}_{2} \mathrm{O}_{4}$ with PPy yielded a positive electrode material with $94.9 \%$ capacity retention after 200 cycles (Jin et al. 2020). 
PEDOT:PSS has been suggested as a binder improving rate performance and stability, in particular, of lithium titanate as negative electrode material in lithium-ion batteries by Zeng et al. (2018), Wang et al. (2014) and Liu et al. (2016). Both ionic and electronic conductivity of the ICP were utilized. A further improvement in performance by reduction of the added amount of conducting carbon was achieved by Eliseeva et al. (2019) with a combination of PEDOT:PSS and carboxymethyl cellulose $\mathrm{CMC}$ as binders. This combination provided sufficient conductivity enabling a significant reduction of the required addition of carbon, it further avoided the chemical incompatibility problems encountered with PVDF as a binder and lithium titanate and yielded superior performance and stability (see Fig. 27). Similar improvements were observed with $\mathrm{MoS}_{2}$ as active positive electrode material and this binder combination (Volkov et al. 2020). Further materials combination of PEDOT:PSS with electrode materials for lithium-ion batteries have been reviewed by Eliseeva et al. (2019), (2020), and Kamenskii et al. (2019).

The effect of conductive binder on the interfacial resistance and $\mathrm{Li}^{+}$-ion transport is somewhat similar to the influence of carbon coating of active grains, when carbonization provides the greatly enhanced surface electronic conductivity of particles. The wrapping of active grains by conducting polymer PEDOT:PSS provides more reliable electrical

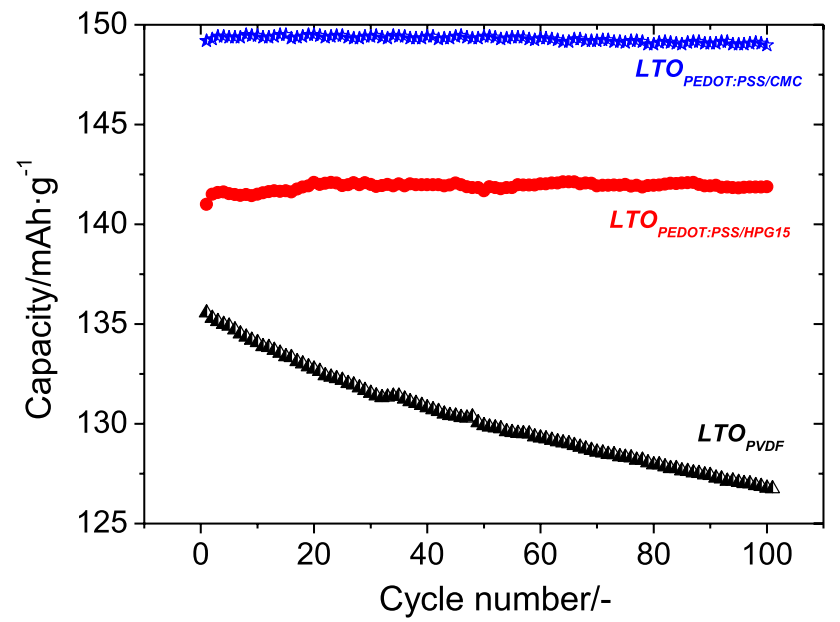

Fig. 27 Cycling performance of $\mathrm{Li}_{4} \mathrm{Ti}_{5} \mathrm{O}_{12}$ with various binder systems, based on data in Eliseeva et al. (2019), Kamenskii et al. (2019) contact between neighboring particles. In combination with ionic conductivity of both ICP components of binder this would greatly enhance the interfacial coupled electron and ion transfer and $\mathrm{Li}^{+}$ion transport in pores around active grains. This is illustrated in Fig. 28, the difference between non-conductive and conductive binders, the possible mechanism of electron and ion pathways in conductive binder is indicated.

The conductive polymer coating of active particles increases the electronic conductivity on the surface of an individual particle and reduces the transfer resistance of ionic and electronic charge. In case of non-conducting PVDF binder, charge transfer occurs only in the region of point contact of active grains with carbon black particles.

Using only PEDOT:PSS as conducting additive resulted in inferior high-rate performance when compared with CNTs in a positive electrode of $\mathrm{LiNi}_{0.5} \mathrm{Co}_{0.2} \mathrm{Mn}_{0.3} \mathrm{O}_{2}$ (Medvedev et al. 2020). The optimized binder and conducting additive combinations addressed above were not included in this comparison.

Chitosan-grafted PANI has been suggested as another binder system for negative silicon electrode for lithium-ion batteries (Rajeev et al. 2020). At 1:1 ratio of both constituents conductivities (both ionic and electronic) and mechanical properties including adhesion were best. $42 \%$ of the initial capacitance were found in the 200th cycle. PEDOT cross-linked with glycerol with PSS as counter anion has been suggested for a negative silicon electrode (Liu et al. 2020a). After 200 cycles the electrode had $68.3 \%$ of its initial capacitance left. A polymeric binder poly(1-pyrenemethyl methacrylate-co-methacrylic acid) (Fig. 29) has been examined for a nanosilicon negative electrode in a lithiumion battery (Zhao et al. 2015). A stable capacity is found after 50 cycles, evidence of the conductivity of the binder (neither ionic nor electronic) is not shown.

The influence of PANI structure (linear, cross-linked, star-like) on performance of a silicon electrode has been examined; star-like PANI turned out to be best performing (Han et al. 2020). A 3-D binder system composed of PANI, polyacrylic acid and phytic acid was used for preparing a negative silicon electrode for a lithium-ion battery (Wang et al. 2019f). 83.6\% capacitance retention were found after 100 deep cycles. PEDOT:PSS has been used together with rGO to prepare nanosilicon particles into a negative
Fig. 28 Electronic and ionic transport in electrode materials (based on Eliseeva et al. 2017)
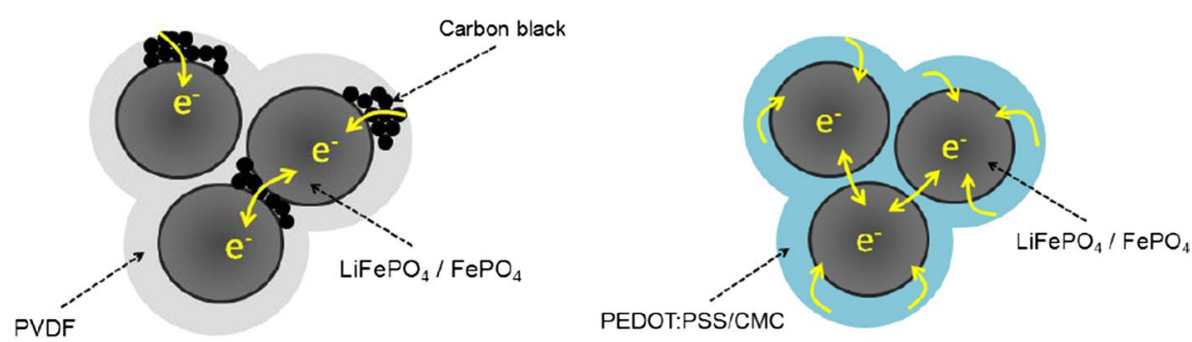


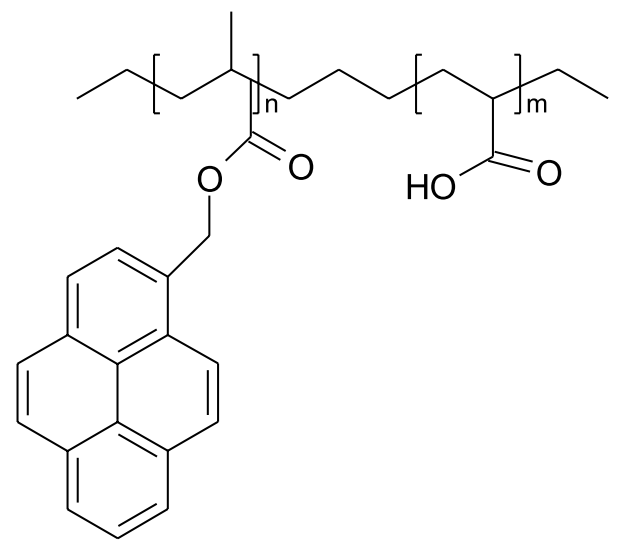

Fig. 29 Poly(1-pyrenemethyl methacrylate-co-methacrylic acid)

electrode showing moderately stable capacity along 500 cycles (Qi et al. 2019). When using $\mathrm{SiO}_{\mathrm{x}}$ as the starting material for a negative silicon electrode in a lithium-ion battery microparticles of this material coated with bilayers of carbon and PEDOT have turned out to be beneficial yielding an electrode with a capacity stable along 1000 cycles (Wu et al. 2020a). Because of environmental concerns watersoluble binders for active masses in secondary batteries are gaining growing attention. A copolymer of polyvinylpyrrolidone and PANI has been reported for use in a silicon electrode for lithium-ion batteries (Zheng et al. 2019). Evidence of hydrogen bonding between the comonomers was somewhat unusually taken as proof of true copolymerization (for a critical examination see also Holze 2011). At optimum composition after 100 cycles $47.3 \%$ of the initial storage capacity of the electrode were left.

Copper foil used as negative electrode support and current collector in lithium-ion batteries has been coated with PANI (Zhang et al. 2020e). Storage capability and stability were increased, and the cell impedance decreased. Corrosion protection could also be achieved with a coating of electrodeposited PPy (Jiang et al. 2020a, b). A reported charge transfer resistance-presumably the corrosion resistance-was increased sevenfold even after $500 \mathrm{~h}$ of contact between coated metal foil and electrolyte solution. No cell performance data were provided. At the positive electrode in lithium-ion batteries an aluminum foil is used as current collector and mechanical support. Its coating with PEDOT by chemical vapor deposition has been suggested (Lepage et al. 2019). A 30\% increase in discharge capacity was attributed to this coating.

PPy has been examined as corrosion protection for a zinc electrode in aqueous $\mathrm{ZnSO}_{4}$ electrolyte solution providing $67 \%$ inhibition efficiency (Nuanwat and Pattananuwat 2019).

Reduced self-discharge and enhanced corrosion protection (75.8\% corrosion inhibition) in an aqueous zinc-ion battery was achieved by coating the zinc electrode with
PANI (Nam et al. 2019); after $24 \mathrm{~h}$ storage $96.9 \%$ of the initial capacitance were still available. A coating with PPy has been suggested for improved control of both plating and stripping of the negative zinc electrode (Zhang et al. 2020f). After 12,000 cycles $96 \%$ of the electrode capacity were still available. An enhanced corrosion protection of PANI coated on the zinc electrode in a zinc-air battery by adding zinc phtaholcyanine has been noticed (Deyab and Mele 2019). Corrosion inhibition grew from $74.8 \%$ without the addition to $97.7 \%$ resulting in increased capacity retention.

Lightweight grids for lead-acid batteries have been prepared from polymers coated with lead (Martha et al. 2006). Corrosion protection of these coatings at both electrodes is particularly important, it was afforded by coating with PANI resulting in batteries with improved gravimetric energy density and high rate capability.

\section{Miscellaneous uses of ICPs}

Solid electrolytes with composites containing various combinations of PPy or PANI have been suggested (Dalas et al. 1995). Gel electrolytes for lithium-ion batteries based on combinations of PANI and polyacrylonitrile have been studied (Amaral et al. 2007). Advantageous electrochemical performance and stability were reported. Enhanced conductivity of PANI by incorporation of polyethyleneoxide has been reported (Yang et al. 2017), this may possibly be useful for enhancing current-carrying properties of electrode materials. Coating of a polypropylene separator with PANI increased wetting with a nonaqueous electrolyte solution resulting in increased ionic conductance (Hao et al. 2019). Coating of a polyethylene separator with particles of $\mathrm{AlF}_{3}$ and a copolymer of EDOT and ethylene glycol yielded decreased thermal shrinkage and improved electrolyte solution uptake resulting in improved cycling performance (Shin et al. 2015). Molecular sieves coated with PEDOT:PSS have been proposed as water scavenger for lithium-ion batteries with NMC as positive electrode (Xue et al. 2020). Coating of the separator for a lithium-ion sulfur battery with a blend of PEDOT:PSS and carbon black resulted in overall performance improvements (Yi et al. 2019). A similar effect was achieved with a coating of porous PPy spheres ( $\mathrm{Li}$ et al. 2019g). To prevent polysulfide diffusion an additional interlayer of carbon fibers coated with PPy has been proposed (Li et al. 2019h). Beyond physical adsorption of polysulfide the interlayer also reduced electrode polarization of the sulfur electrode. Vaporphase deposition of PPy on a commercial Celgard separator yielded a separator with several advantages ( $\mathrm{Li}$ et al. 2019i).

An interlayer of PPy on carbon cloth assisted in loading $\mathrm{Li}_{4} \mathrm{Ti}_{5} \mathrm{O}_{12}$ nanosheets for use as negative electrode in a sodium-ion battery (Jiang et al. 2020a). After 1100 cycles $96.6 \%$ of the initial capacitance were retained. 
A composite of CNTs and PEDOT has been suggested as mechanical support and current collector instead of metal foils, when incorporated with further active mass, e.g., positive electrodes have been prepared (Rousselot et al. 2020).

A skeleton of PEDOT:PSS keeps an ionic liquid providing ion channels in an aqueous zinc-polysulfide battery in place (Zhao et al. 2020).

ICPs have been examined as coatings in the positive electrodes of metal air batteries (Cao et al. 2020).

Modification of the frequently used lignosulfonate as an expander in the negative electrode of a lead acid battery (Pavlov 2006) with PANI has been proposed (Chen et al. 2020b). Significant overall performance improvements were noted.

\section{Precursors and templates}

Several ICPs can be prepared chemically as well as electrochemically in a variety of shapes and morphologies, for example see Dubal et al. (2016b), Stejskal et al. (2010) and Stejskal and Trchova (2018). These morphologies may be suitable as electrode material themselves, but they may also be used as precursor in subsequent carbonization or pyrolysis steps yielding carbon structures related to the advantageous structural details of the precursor. A particular advantage of the use of ICPs as precursor materials in such transformation is the easy introduction of heteroatoms (nitrogen, sulfur) into the resulting carbon material. These additions (sometimes slightly misleadingly called dopants) frequently result in enhanced electronic conduction (for example, see (Zhang et al. 2020b, 2020d)).

Dubal et al. (2019) have carbonized PPy-nanopipes yielding a host material for the negative electrode of a lithium-ion capacitor, together with the pristine nanopipes as positive electrode they assembled a capacitor keeping 93\% of its initial capacitance after 2000 cycles. Whereas the positive electrode shows pseudocapacitive behavior (see Holze 2017), the negative electrode is a battery-type electrode.

In a simplified approach an ICP can be used as a heteroatom source for preparation of, e.g., nitrogen-containing carbon materials ( $\mathrm{Li}$ et al. 2019b). Mesoporous spheres of $\mathrm{TiO}_{2}$ embedded in PPy yielded after carbonization a negative electrode material for a lithium-ion battery (Chen et al. 2020a) $53 \%$ of the initial electrode capacity were left after 500 cycles.

The particular morphology, e.g., nanotubes, can be used as template (Wei et al. 2019a) for active material deposition first, followed by pyrolysis or carbonization.

\section{Conclusions}

Intrinsically conducting polymers, their copolymers with redox-active molecules, and their composites with such molecules have attracted growing attention in secondary battery research and development. Their application ranges from being the sole active material to use as a binder, protective coating of active material, precursor for active masses, and separator. However, despite the significant progress on all aspects, stability of the obtained electrodes and cell constituents varies widely and too much for practical use; further research should be focused on this aspect which is definitely of major practical importance. When combined with more attention to a rational electrode design in terms of architecture and possible mass utilization keeping an eye on possible and actually utilized capabilities of the polymer component(s) in an actual electrode obtained materials carefully and comparably examined for performance and stability will provide attractive options in electrochemical energy technology.

Acknowledgements Financial support provided within research projects at St. Petersburg State University Grant № 26455158 and Grant № 70037840 is appreciated. Preparation of this communication has been supported in various ways by the Alexander von Humboldt-Foundation, Deutscher Akademischer Austauschdienst, Fonds der Chemischen Industrie, Deutsche Forschungsgemeinschaft, National Basic Research Program of China, and Natural Science Foundation of China.

Funding Open Access funding enabled and organized by Projekt DEAL.

Open Access This article is licensed under a Creative Commons Attribution 4.0 International License, which permits use, sharing, adaptation, distribution and reproduction in any medium or format, as long as you give appropriate credit to the original author(s) and the source, provide a link to the Creative Commons licence, and indicate if changes were made. The images or other third party material in this article are included in the article's Creative Commons licence, unless indicated otherwise in a credit line to the material. If material is not included in the article's Creative Commons licence and your intended use is not permitted by statutory regulation or exceeds the permitted use, you will need to obtain permission directly from the copyright holder. To view a copy of this licence, visit http://creativecommons.org/licenses/by/4.0/.

\section{References}

Admassie S, Ajjan FN, Elfwing A, Inganäs O (2016) Biopolymer hybrid electrodes for scalable electricity storage. Mater Horiz 3:174-185. https://doi.org/10.1039/c5mh00261c

Ahn S, Noguchi T, Momma T, Nara H, Yokoshima T, Togasaki N, Osaka T (2020) Facile fabrication of sulfur/KetjenblackPEDOT:PSS composite as a cathode with improved cycling performance for lithium sulfur batteries. Chem Phys Lett 749:137426. https://doi.org/10.1016/j.cplett.2020.137426

Ákerlund L, Emanuelsson R, Hernández G, Ruipérez F, Casado N, Brandell D, Strømme M, Mecerreyes D, Sjödin M (2019) In situ investigations of a proton trap material: a PEDOT-based copolymer with hydroquinone and pyridine side groups having robust cyclability in organic electrolytes and ionic liquids. ACS Appl Energy Mater 2:4486-4495. https://doi.org/10.1021/acsae m.9b00735 
Amaral FA, Dalmolin C, Canobre SC, Bocchi N, Rocha-Filho RC, Biaggio SR (2007) Electrochemical and physical properties of poly(acrylonitrile)/poly(vinyl acetate)-based gel electrolytes for lithium ion batteries. J Power Sources 164:379-385. https://doi. org/10.1016/j.jpowsour.2006.10.049

Armand M, Tarascon JM (2008) Building better batteries. Nature 451:652-657. https://doi.org/10.1038/451652a

Armand M, Grugeon S, Vezin H, Laruelle S, Ribiere P, Poizot P, Tarascon JM (2009) Conjugated dicarboxylate anodes for Li-ion batteries. Nat Mater 8:120-125. https://doi.org/10.1038/NMAT2372

Beck F, Euler KJ (1984) Elektrochemische Energiespeicher. VDEVerlag $\mathrm{GmbH}$, Berlin

Bocchetta P, Frattini D, Tagliente M, Selleri F (2020) Electrochemical deposition of polypyrrole nanostructures for energy applications: a review. Curr Nanosci 16:462-477. https://doi. org/10.2174/1573413715666190717113600

Cao X, Zhang J, Zhu L (2015) Preparation of $\mathrm{LiV}_{3} \mathrm{O}_{8}$ /polypyrrole and their derived $\mathrm{LiV}_{3} \mathrm{O}_{8}$ carbon composites as cathode materials for lithium rechargeable batteries. J Nanosci Nanotechnol 15:7081-7086. https://doi.org/10.1166/jnn.2015.10546

Cao D, Shen X, Wang Y, Liu J, Shi H, Gao X, Liu X, Fu L, Wu Y, Chen $\mathrm{Y}$ (2020) Conductive polymer coated cathodes in $\mathrm{Li}-\mathrm{O}_{2}$ batteries. ACS Appl Energy Mater 3:951-956. https://doi.org/10.1021/ acsaem.9b02024

Casado N, Mecerreyes D (2020) Introduction to redox polymers: classification, characterization methods and main applications. In: Casado N, Mecerreyes D (eds) Redox polymers for energy and nanomedicine. RSC, Cambridge, pp 1-26

Chang CC, Her LJ, Hong JL (2005) Copolymer from electropolymerization of thiophene and 3,4-ethylenedioxythiophene and its use as cathode for lithium ion battery. Electrochim Acta 50:44614468. https://doi.org/10.1016/j.electacta.2005.02.008

Chelladurai K, Venkatachalam P, Rengapillai S, Liu WR, Huang CH, Marimuthu S (2020) Effect of polyaniline on sulfur/sepiolite composite cathode for lithium-sulfur batteries. Polymers 12:755. https://doi.org/10.3390/POLYM12040755

Chen Y (2019) A review of polyaniline based materials as anodes for lithium ion batteries. IOP Conf Ser Mater Sci Eng 677:022115. https://doi.org/10.1088/1757-899X/677/2/022115

Chen HW, Li C (2020) PEDOT: fundamentals and its nanocomposites for energy storage. Chin J Polym Sci 38:435-448. https://doi. org/10.1007/s10118-020-2373-2

Chen H, Armand M, Demailly G, Dolhem F, Poizot P, Tarascon JM (2008) From biomass to a renewable $\mathrm{Li}_{\mathrm{x}} \mathrm{C}_{6} \mathrm{O}_{6}$ organic electrode for sustainable $\mathrm{Li}$-ion batteries. Chemsuschem 1:348-355. https ://doi.org/10.1002/cssc.200700161

Chen HY, Armand M, Courty M, Jiang M, Grey CP, Dolhem F, Tarascon JM, Poizot P (2009) Lithium salt of tetrahydroxybenzoquinone: toward the development of a sustainable Li-ion battery. J Am Chem Soc 131:8984-8988. https://doi.org/10.1021/ja902 4897

Chen Y, Luo W, Carter M, Zhou K, Dai J, Fu K, Lacey S, Li T, Wan J, Han X, Bao Y, Hu L (2015) Organic electrode for non-aqueous potassium-ion batteries. Nano Energy 18:205-211. https://doi. org/10.1016/j.nanoen.2015.10.015

Chen C, Hong X, Chen A, Xu T, Lu L, Lin S, Gao Y (2016) Electrochemical properties of poly(aniline-co-N-methylthionine) for zinc-conducting polymer rechargeable batteries. Electrochim Acta 190:240-247. https://doi.org/10.1016/j.elect acta.2015.12.125

Chen Q, Yuan F, Yin SM, Zhu M, Cai GS (2020a) Pomegranate-like C@TiO2mesoporous honeycomb spheres for high performance lithium ion batteries. Nanotechnology 31:435410. https://doi. org/10.1088/1361-6528/aba302

Chen C, Liu Y, Chen Y, Li X, Cheng J, Chen S, Lin J, Zhang X, Zhang Y (2020b) Effect of polyaniline-modified lignosulfonate added to the negative active material on the performance of lead-acid battery. Electrochim Acta 338:135859. https://doi.org/10.1016/j. electacta.2020.135859

Chen S, Li K, Hui KS, Zhang J (2020c) Regulation of lamellar structure of vanadium oxide via polyaniline intercalation for high-performance aqueous zinc-ion battery. Adv Funct Mater 30:202003890. https://doi.org/10.1002/adfm.202003890

Chen-Yang YW, Li JL, Wu TL, Wang WS, Hon TF (2004) Electropolymerization and electrochemical properties of ( $N$-hydroxyalkyl) pyrrole/pyrrole copolymers. Electrochim Acta 49:2031-2040. https://doi.org/10.1016/j.electacta.2003.12.033

Chhin D, Padilla-Sampson L, Malenfant J, Rigaut V, Nazemi A, Schougaard SB (2019) Conducting polymers doped with bifunctional copolymers for improved organic batteries. ACS Appl Energy Mater 2:7781-7790. https://doi.org/10.1021/acsaem.9b01104

Cho JS, Sato S, Takeoka S, Tsuchida E (2001) Synthesis of disulfidecontaining aniline and copolymerization with aniline. Macromolecules 34:2751-2756. https://doi.org/10.1021/ma001802h

Cíntora-Juárez D, Pérez-Vicente C, Ahmad S, Tirado JL (2014) Improving the cycling performance of $\mathrm{LiFePO}_{4}$ cathode material by poly(3,4-ethylenedioxythiopene) coating. RSC Adv 4:26108. https://doi.org/10.1039/c4ra05286b

Cíntora-Juárez D, Pérez-Vicente C, Kazim S, Ahmad S, Tirado JL (2015) Judicious design of lithium iron phosphate electrodes using poly(3,4-ethylenedioxythiophene) for high performance batteries. J Mater Chem A 3:14254-14262. https://doi. org/10.1039/C5TA03542B

Craig B, Skylaris CK, Schoetz T, de León CP (2020) A computational chemistry approach to modelling conducting polymers in ionic liquids for next generation batteries. Energy Rep 6:198208. https://doi.org/10.1016/j.egyr.2020.03.025

Dai S, Feng Y, Wang P, Wang H, Liang H, Wang R, Linkov V, Ji S (2019) Highly conductive copolymer/sulfur composites with covalently grafted polyaniline for stable and durable lithiumsulfur batteries. Electrochim Acta 321:134678. https://doi. org/10.1016/j.electacta.2019.134678

Dalas E, Tsamouras D, Bouropoulos N (1995) Primary solid state batteries. Ionics 1:235-241. https://doi.org/10.1007/BF024 26023

Das PR, Komsiyska L, Osters O, Wittstock G (2015) PEDOT: PSS as a functional binder for cathodes in lithium ion batteries. J Electrochem Soc 162:A674-A678. https://doi.org/10.1149/2.05815 04 jes

Deyab MA, Mele G (2019) Polyaniline/Zn-phthalocyanines nanocomposite for protecting zinc electrode in $\mathrm{Zn}$-air battery. $\mathrm{J}$ Power Sources 443:227264. https://doi.org/10.1016/j.jpows our.2019.227264

Díez N, Sevilla M, Fuertes AB (2020) N/S-Co-doped porous carbon nanoparticles serving the dual function of sulfur host and separator coating in lithium-sulfur batteries. ACS Appl Energy Mater 3:3397-3407. https://doi.org/10.1021/acsaem.9b02221

Dinh HC, Lim H, Park KD, Yeo IH, Kang Y, Mho SI (2013) Longterm cycle stability at a high current for nanocrystalline $\mathrm{LiFePO}_{4}$ coated with a conductive polymer. Adv Nat Sci Nanosci Nanotechnol 4:015011. https://doi.org/10.1088/2043-6262/4/1/015011

Du P, Wei W, Dong Y, Liu D, Wang Q, Peng Y, Chen S, Liu P (2019) Sulfur impregnation in polypyrrole-modified $\mathrm{MnO}_{2}$ nanotubes: efficient polysulfide adsorption for improved lithium-sulfur battery performance. Nanoscale 11:10097-10105. https://doi. org/10.1039/c8nr10353d

Dubal DP, Wu Y, Holze R (2015) Supercapacitors as fast storage systems for electric energy. Bunsen-Magazin 17:216-227

Dubal DP, Wu YP, Holze R (2016a) Supercapacitors: from the Leyden jar to electric busses. Chemtexts 2:13. https://doi.org/10.1007/ s40828-016-0032-6 
Dubal DP, Chodankar NR, Caban-Huertas Z, Wolfart F, Vidotti M, Holze R, Lokhande CD, Gomez-Romero P (2016b) Synthetic approach from polypyrrole nanotubes to nitrogen doped pyrolyzed carbon nanotubes for asymmetric supercapacitors. J Power Sources 308:158-165. https://doi.org/10.1016/j.jpows our.2016.01.074

Dubal D, Jagadale A, Chodankar NR, Kim DH, Gomez-Romero P, Holze R (2019) Polypyrrole nanopipes as a promising cathode material for Li-ion batteries and $\mathrm{Li}$-ion capacitors: two-in-one approach. Energy Technol 7:193-200. https://doi.org/10.1002/ ente. 201800551

Eliseeva SN, Apraksin RV, Tolstopjatova EG, Kondratiev VV (2017) Electrochemical impedance spectroscopy characterization of $\mathrm{LiFePO}_{4}$ cathode material with carboxymethylcellulose and poly-3,4-ethylendioxythiophene/polystyrene sulfonate. Electrochim Acta 227:357-366. https://doi.org/10.1016/j.elect acta.2016.12.157

Eliseeva SN, Shkreba EV, Kamenskii MA, Tolstopjatova EG, Holze R, Kondratiev VV (2019) Effects of conductive binder on the electrochemical performance of lithium titanate anodes. Solid State Ion 333:18-29. https://doi.org/10.1016/j.ssi.2019.01.011

Eliseeva SN, Kamenskii MA, Tolstopyatova EG, Kondratiev VV (2020) Effect of combined conductive polymer binder on the electrochemical performance of electrode materials for lithiumion batteries. Energies 13:2163. https://doi.org/10.3390/en130 92163

Feng L, Zhang W, Zhang W, Wang R, Wang R, Xu L, Li D, Xiao C, Zhang Y, Zhang Y (2020) Preparation of CuO@PPy hybrid nanomaterials as high cyclic stability anode of lithium-ion battery. Micro Nano Lett 15:441-445. https://doi.org/10.1049/ mnl.2019.0409

Flouda P, Quinn AH, Patel AG, Loufakis D, Lagoudas DC, Lutkenhaus JL (2020) Branched aramid nanofiber-polyaniline electrodes for structural energy storage. Nanoscale 12:16840-16850. https:// doi.org/10.1039/d0nr04573j

Fu L, Qu Q, Holze R, Kondratiev VV, Wu Y (2019) Composites of metal oxides and intrinsically conducting polymers as supercapacitor electrode materials: the best of both worlds? J Mater Chem A 7:14937-14970. https://doi.org/10.1039/C8TA10587A

Gao Y, Xiong K, Xu H, Zhu B (2019) Enhanced high-rate and lowtemperature electrochemical properties of $\mathrm{LiFePO}_{4} /$ polypyrrole cathode materials for lithium-ion batteries. Int J Electrochem Sci 14:3408-3417. https://doi.org/10.20964/2019.04.01

Gao S, Yang L, Shao J, Qu Q, Wu Y, Holze R (2020a) Construction of hierarchical hollow $\mathrm{MoS}_{2} /$ carbon microspheres for enhanced lithium storage performance. J Electrochem Soc 167:100525. https://doi.org/10.1149/1945-7111/ab98b0

Gao X, Huang Y, Guang Z, Li X (2020b) Constructing a multifunctional globular polypyrrole slurry cladding carbon aerogel/sulfur cathode for high-performance lithium-sulfur batteries. Energy Fuels 34:3931-3940. https://doi.org/10.1021/acs.energyfuel s.0c00074

Gao L, Cao Y, Wang J, Ren H, Wang J, Huang J (2020c) Construction of polypyrrole coated hollow cobalt manganate nanocages as an effective sulfur host for lithium-sulfur batteries. Ceram Int 46:18224-18233. https://doi.org/10.1016/j.ceramint.2020.04.145

Ge Y, Xie X, Roscher J, Holze R, Qu Q (2020) How to measure and report the capacity of electrochemical double layers, supercapacitors, and their electrode materials. J Solid State Electrochem 24:3215-3230. https://doi.org/10.1007/s10008-020-04804-x

Ge Y, Liu Z, Wu Y, Holze R (2021) On the utilization of supercapacitor electrode materials. Electrochim Acta 366:137390. https://doi. org/10.1016/j.electacta.2020.137390

Ghosh A, Kumar A, Roy A, Panda MR, Kar M, MacFarlane DR, Mitra S (2019) Three-dimensionally reinforced freestanding cathode for high-energy room-temperature sodium-sulfur batteries. ACS
Appl Mater Interfaces 11:14101-14109. https://doi.org/10.1021/ acsami.9b00203

Gilhotra C, Chander M, Sanjay (2019) A review: conducting polyaniline polymer. AIP Conf Proc 2142:150008. https://doi. org/10.1063/1.5122557

Dong C, Deng F, Tsui CP, Xue Z, Ye YS, Tang CY, Zhou X, Xie X (2014) PANI-PEG copolymer modified LiFePO4 as a cathode material for high-performance lithium ion batteries. J Mater Chem A 2:19315-19323. https://doi.org/10.1039/c4ta04089a

Guo C, Tian S, Chen B, Liu H, Li J (2020) Constructing $\alpha-\mathrm{MnO}_{2} @ P P y$ core-shell nanorods towards enhancing electrochemical behaviors in aqueous zinc ion battery. Mater Lett 262:127180. https:// doi.org/10.1016/j.matlet.2019.127180

Han P, Chung SH, Manthiram A (2019) A designing a high-loading sulfur cathode with a mixed ionic-electronic conducting polymer for electrochemically stable lithium-sulfur batteries. Energy Storage Mater 17:317-324. https://doi.org/10.1016/j.ensm.2018.11.002

Han R, Liu W, He X, Jiang P, Chen Y (2020) Molecularly engineered conductive polymer binder enables stable lithium storage of Si. Ind Eng Chem Res 59:2680-2688. https://doi.org/10.1021/ acs.iecr.9b05838

Hao Z, Wu C, Zhang Q, Liu J, Wang H (2019) A sandwich-structured separator based on in situ coated polyaniline on polypropylene membrane for improving the electrolyte wettability in lithium-ion batteries. Int J Energy Res 43:8049-8056. https:// doi.org/10.1002/er.4796

He Y, Wang X, Zhang P, Huang H, Li X, Shui Y, Chen B, Guo Z (2019) A versatile integrated rechargeable lead dioxidepolyaniline system with energy storage mechanism transformation. Energy 183:358-367. https://doi.org/10.1016/j.energ y.2019.06.144

Holze R (2011) Copolymers-a refined way to tailor intrinsically conducting polymers. Electrochim Acta 56:10479-10492. https:// doi.org/10.1016/j.electacta.2011.04.013

Holze R (2017) From current peaks to waves and capacitive currentson the origins of capacitor-like electrode behavior. J Solid State Electrochem 21:2601-2607. https://doi.org/10.1007/s1000 8-016-3483-1

Holze R (2020) Composites and copolymers containing redox-active molecules and intrinsically conducting polymers as active masses for supercapacitor electrodes-an introduction. Polymers 12:1835. https://doi.org/10.3390/polym12081835

Holze R, Wu YP (2014) Intrinsically conducting polymers in electrochemical energy technology: trends and progress. Electrochim Acta 122:93-107. https://doi.org/10.1016/j.elect acta.2013.08.100

Holze R, Wu YP (2021) Battery and/or supercapacitor? —on the merger of two electrochemical storage families. Submitted to ChemTexts

Hong X, Liu Y, Li Y, Wang X, Fu J, Wang X (2020) Application progress of polyaniline, polypyrrole and polythiophene in lithiumsulfur batteries. Polymers 12:331. https://doi.org/10.3390/polym 12020331

Hou L, Bao R, Denis DK, Sun X, Zhang J, Zaman FU, Yuan C (2019) Synthesis of ultralong $\mathrm{ZnFe}_{2} \mathrm{O}_{4} @$ polypyrrole nanowires with enhanced electrochemical Li-storage behaviors for lithiumion batteries. Electrochim Acta 306:198-208. https://doi. org/10.1016/j.electacta.2019.03.121

Hu J, Ren Y, Zhang L (2020) Dual-confined $\mathrm{SeS}_{2}$ cathode based on polyaniline-assisted double-layered micro/mesoporous carbon spheres for advanced $\mathrm{Li}_{-} \mathrm{SeS}_{2}$ battery. J Power Sources 455:227955. https://doi.org/10.1016/j.jpowsour.2020.227955

Huang S, Wang X, Hu R, Wang X, Yang X, Zhao N, Lei W, Zhu L, Peng J (2020) Polypyrrole-S-coated MWCNT composites as cathode materials for lithium-sulfur batteries. Ionics 26:54555462. https://doi.org/10.1007/s11581-020-03736-w 
Ignatova AA, Kozlov AV, Shestakov AF, Chernyak AV, Yarmolenko OV, Troshin PA (2017) Insight in the degradation of polyquinone-based cathode material in lithium-organic battery under cycling. Mendeleev Commun 27:524-526. https://doi. org/10.1016/j.mencom.2017.09.032

Inzelt G (2008) Conducting polymers. In: Scholz F (ed). Springer, Berlin

Izwan Misnon I, Krishnan SG, Jose R (2020) Thin chemisorbed polyaniline film on cobalt oxide as an electrode for hybrid energy storage devices. ChemistrySelect 5:7973-7983. https://doi. org/10.1002/slct.202001879

Jiang L, Dong C, Jin B, Wen Z, Jiang Q (2019) $\mathrm{ZnFe}_{2} \mathrm{O}_{4} @ \mathrm{PPy}$ core-shell structure for high-rate lithium-ion storage. J Electroanal Chem 851:113442. https://doi.org/10.1016/j.jelec hem.2019.113442

Jiang C, Ye Z, Ye H, Zou Z (2020a) $\mathrm{Li}_{4} \mathrm{Ti}_{5} \mathrm{O}_{12}$ @ carbon cloth composite with improved mass loading achieved by a hierarchical polypyrrole interlayer assisted hydrothermal process for robust free-standing sodium storage. Appl Surf Sci 504:144464. https ://doi.org/10.1016/j.apsusc.2019.144464

Jiang X, Chen J, Yang Y, Lv Y, Ren Y, Li W, Li C (2020b) Corrosion protection of copper current collector of lithium-ion batteries by doped polypyrrole coatings. Int J Electrochem Sci 15:2667-2676. https://doi.org/10.20964/2020.03.15

Jin R, Liu J, Qiu H, Xu C, Weng L, Liu C, Zeng Y (2020) Synthesis of porous nanosheet-assembled $\mathrm{ZnFe}_{2} \mathrm{O}_{4} @$ polypyrrole yolkshell microspheres as anode materials for high-rate lithiumion batteries. J Electroanal Chem 863:114038. https://doi. org/10.1016/j.jelechem.2020.114038

Jing Y, Liang Y, Gheytani S, Yao Y (2017) Cross-conjugated oligomeric quinones for high performance organic batteries. Nano Energy 37:46-52. https://doi.org/10.1016/j.nanoe n.2017.04.055

Jouhara A, Dupre N, Gaillot AC, Guyomard D, Dolhem F, Poizot P (2018) Raising the redox potential in carboxyphenolate-based positive organic materials via cation substitution. Nat Commun 9:4401. https://doi.org/10.1038/s41467-018-06708-x

Kaiser MR, Han Z, Wang J (2019) Electro-polymerized polypyrrole film for fabrication of flexible and slurry-free polypyrrole-sulfurpolypyrrole sandwich electrode for the lithium-sulfur battery. J Power Sources 437:226925. https://doi.org/10.1016/j.jpows our.2019.226925

Kamenskii MA, Eliseeva SN, Holze R, Kondratiev VV (2019) Performance of negative lithium titanate electrodes containing minimized amounts of conducting polymer and modified guar gum as binder. J Electrochem Soc 166:A3354-A3361. https://doi. org/10.1149/2.0791914jes

Karlsson C, Huang H, Strømme M, Gogoll A, Sjödin M (2014) Quinone pendant group kinetics in poly(pyrrol-3-ylhydroquinone). J Electroanal Chem 735:95-98. https://doi.org/10.1016/j.jelec hem.2014.10.013

Key J, Feng Y, Shen J, Wang P, Wang H, Liang H, Wang R, Ji S (2020) A highly crosslinked and conductive sulfur-rich copolymer with grafted polyaniline for stable cycling lithium-sulfur batteries. J Electrochem Soc 167:020530. https://doi.org/10.1149/19457111/ab6bc0

Khrizanforov M, Shekurov R, Miluykov V, Gilmanova L, Kataeva O, Yamaleeva Z, Gerasimova T, Ermolaev V, Gubaidullin A, Laskin A, Budnikova Y (2019) Excellent supercapacitor and sensor performance of robust cobalt phosphinate ferrocenyl organic framework materials achieved by intrinsic redox and structure properties. Dalton Trans 48:16986-16992. https://doi. org/10.1039/c9dt03592c

Kiai MS, Kizil H (2019) Enhanced performance of Li-S battery with polymer doped potassium functionalized graphene interlayers as effective polysulfide barrier. J Electroanal Chem 851:113405. https://doi.org/10.1016/j.jelechem.2019.113405

Kim JK, Cheruvally G, Choi JW, Ahn JH, Lee SH, Choi DS, Song CE (2007) Effect of radical polymer cathode thickness on the electrochemical performance of organic radical battery. Solid State Ion 178:1546-1551. https://doi.org/10.1016/j.ssi.2007.09.009

Kim JMM, Park HSS, Park JH, Kim TH, Song HK, Lee SY (2014) Conducting polymer-skinned electroactive materials of lithiumion batteries: ready for monocomponent electrodes without additional binders and conductive agents. ACS Appl Mater Interfaces 6:12789-12797. https://doi.org/10.1021/am502736m

Kim DS, Yoo H, Park MS, Kim H (2019a) Boosting the sodium storage capability of Prussian blue nanocubes by overlaying PEDOT:PSS layer. J Alloys Compd 791:385-390. https://doi.org/10.1016/j. jallcom.2019.03.317

Kim T, Ono LK, Qi Y (2019b) Elucidating the mechanism involved in the performance improvement of lithium-ion transition metal oxide battery by conducting polymer. Adv Mater Interfaces 6:1801785. https://doi.org/10.1002/admi.201801785

Kim J, Elabd A, Chung SY, Coskun A, Choi JW (2020) Covalent triazine frameworks incorporating charged polypyrrole channels for high-performance lithium-sulfur batteries. Chem Mater 32:4185-4193. https://doi.org/10.1021/acs.chemmater.0c00246

Kita T, Daifuku H, Fujio R, Fuse T, Kawagoe T, Masuda Y, Matsunaga T, Ogawa M (1986) Properties of polyaniline secondary battery. J Electrochem Soc 133:C291-C291

Kuwabata S, Masui S, Yoneyama H (1999) Charge-discharge properties of composites of $\mathrm{LiMn}_{2} \mathrm{O}_{4}$ and polypyrrole as positive electrode materials for $4 \mathrm{~V}$ class of rechargeable Li batteries. Electrochim Acta 44:4593-4600. https://doi.org/10.1016/S0013 -4686(99)00178-4

Lai X, Hu G, Peng Z, Tong H, Lu Y, Wang Y, Qi X, Xue Z, Huang Y, Du K, Cao Y (2019) Surface structure decoration of high capacity $\mathrm{Li}_{1.2} \mathrm{Mn}_{0.54} \mathrm{Ni}_{0.13} \mathrm{Co}_{0.13} \mathrm{O}_{2}$ cathode by mixed conductive coating of $\mathrm{Li}_{1.4} \mathrm{Al}_{0.4} \mathrm{Ti}_{1.6}\left(\mathrm{PO}_{4}\right)_{3}$ and polyaniline for lithium-ion batteries. J Power Sources 431:144-152. https://doi.org/10.1016/j. jpowsour.2019.05.044

Lan Q, Yang Y, Song Z, Liu N, Qin J, Men F, Zhan H (2020) PEDOT:PSS dual-function film initiated 1,3-dioxolane polymerization in Li/S cells. ACS Appl Energy Mater 3:3586-3595. https://doi.org/10.1021/acsaem.0c00083

Le Gall T, Reiman KH, Grossel MC, Owen JR (2003) Poly(2,5-dihydroxy-1,4-benzoquinone-3,6-methylene): a new organic polymer as positive electrode material for rechargeable lithium batteries. J Power Sources 119-121:316-320. https://doi.org/10.1016/S0378 -7753(03)00167-8

Lee MH, Hong HT, Rhee SB (1995) Preparation of polypyrrole doped with ferrocenic polymer dopants. SynthMet 69:515-516. https ://doi.org/10.1016/0379-6779(94)02551-9

Lepage D, Michot C, Liang G, Gauthier N, Schougaard SB (2011) A soft chemistry approach to coating of $\mathrm{LiFePO}_{4}$ with a conducting polymer. Angew Chem Int Ed 50:6884-6887. https://doi. org/10.1002/anie.201101661

Lepage D, Savignac L, Saulnier M, Gervais S, Schougaard SB (2019) Modification of aluminum current collectors with a conductive polymer for application in lithium batteries. Electrochem Commun 102:1-4. https://doi.org/10.1016/j.elecom.2019.03.009

Li Z, Gong L (2020) Research progress on applications of polyaniline (PANI) for electrochemical energy storage and conversion. Materials 13:548. https://doi.org/10.3390/ma13030548

Li F, Zou Y, Wang S, Fang L, Lutkenhaus JL (2017) Scalable synthesis and multi-electron transfer of aniline/fluorene copolymer for solution-processable battery cathodes. Macromol Rapid Commun 38:700067. https://doi.org/10.1002/marc.201700067

Li P, Deng J, Li J, Guo J, Zeng M, Wang L, Wang R, Tang M (2019h) Bifunctional interlayer for capturing polysulfide in $\mathrm{Li}-\mathrm{S}$ battery. 
J Mater Sci 54:11983-11990. https://doi.org/10.1007/s1085 3-019-03755-7

Li B, Sun Z, Zhao Y, Bakenov Z (2019g) A novel hierarchically porous polypyrrole sphere modified separator for lithium-sulfur batteries. Polymers 11:1344. https://doi.org/10.3390/polym11081344

Li Y, Wang W, Liu X, Mao E, Wang M, Li G, Fu L, Li Z, Eng AYS, She ZW, Sun Y (2019i) Engineering stable electrode-separator interfaces with ultrathin conductive polymer layer for highenergy-density Li-S batteries. Energy Storage Mater 23:261268. https://doi.org/10.1016/j.ensm.2019.05.005

Li X, Lv R, Zou S, Na B, Liu P, Ma Y, Liu H (2019d) Polyaniline nanopillars on surface cracked carbon fibers as an ultrahigh-performance cathode for a flexible rechargeable aqueous $\mathrm{Zn}$-ion battery. Compos Sci Technol 180:71-77. https://doi.org/10.1016/j. compscitech.2019.05.016

Li X, Xie X, Lv R, Na B, Wang B, He Y (2019j) Nanostructured polypyrrole composite aerogels for a rechargeable flexible aqueous $\mathrm{Zn}$-ion battery with high rate capabilities. Energy Technol 7:1801092. https://doi.org/10.1002/ente.201801092

Li F, Zhu M, Luo Z, Guo L, Bian Z, Li Y, Luo K (2019b) Nitrogen-doped graphene derived from polyaniline/graphene oxide composites with improved capacity and cyclic performance of Li-O $\mathrm{O}_{2}$ battery. J Solid State Electr 23:2391-2399. https://doi. org/10.1007/s10008-019-04339-w

Li P, Fang Z, Zhang Y, Mo C, Hu X, Jian J, Wang S, Yu D (2019c) A high-performance, highly bendable quasi-solid-state zincorganic battery enabled by intelligent proton-self-buffering copolymer cathodes. J Mater Chem A 7:17292-17298. https:// doi.org/10.1039/c9ta04185k

Li B, Li G, Zhang D, Fan J, Chen D, Ge Y, Lin F, ZhengC LL (2019f) Unveiling the impact of the polypyrrole coating layer thickness on the electrochemical performances of $\mathrm{LiNi}_{0.5} \mathrm{Co}_{0.2} \mathrm{Mn}_{0.3} \mathrm{O}_{2}$ in Li-ion battery. ChemistrySelect 4:6354-6360. https://doi. org/10.1002/slct.201901112

Li H, Zhang B, Ou X, Zhou Q, Wang C, Peng C, Zhang J (2019e) Core-shell structure of $\mathrm{SnO}_{2} @ \mathrm{C} / \mathrm{PEDOT}$ : PSS microspheres with dual protection layers for enhanced lithium storage performance. ChemElectroChem 6:2182-2188. https://doi. org/10.1002/celc.201801774

Li S, Wang C, Yu J, Han Y, Lu Z (2019a) Understanding the role of conductive polymer in thermal lithiation and battery performance of Li-Sn alloy anode. Energy Stor Mater 20:7-13. https://doi. org/10.1016/j.ensm.2018.11.030

Li Z, Huang Y, Zhang J, Jin S, Zhang S, Zhou H (2020b) One-step synthesis of $\mathrm{MnO}_{\mathrm{x}} / \mathrm{PPy}$ nanocomposite as a high-performance cathode for a rechargeable zinc-ion battery and insight into its energy storage mechanism. Nanoscale 12:4150-4158. https://doi. org/10.1039/c9nr09870d

Li Y, Wang H, Yn T, Li J, Kan J (2020a) Cheap and eco-friendly synthesis of polyaniline and performance of aqueous $\mathrm{Zn}$-polyaniline battery. Int J Electrochem Sci 15:5956-5965. https://doi. org/10.20964/2020.07.61

Liang X, Gao G, Jiang X, Zhang W, Bi W, Wang J, Du Y, Wu G (2020) Preparation of hydrophobic PPy Coated $\mathrm{V}_{2} \mathrm{O}_{5}$ yolk-shell nanospheres-based cathode materials with excellent cycling performance. ACS Appl Energy Mater 3:2791-2802. https://doi. org/10.1021/acsaem.9b02451

Liao J, Hu Q, Mu J, Chen F, He X, Chen F, Wen Z, Chen C (2020) Introducing a conductive pillar: a polyaniline intercalated layered titanate for high-rate and ultra-stable sodium and potassium ion storage. Chem Commun 56:8392-8395. https://doi.org/10.1039/ d0cc01107j

Liedel C, Wang X, Antonietti M (2018) Biobased polymer cathodes with enhanced charge storage. Nano Energy 53:536-543. https ://doi.org/10.1016/j.nanoen.2018.09.012
Liu LL, Wang XJ, Zhu YS, Hu CL, Wu YP, Holze R (2013) Polypyrrole-coated $\mathrm{LiV}_{3} \mathrm{O}_{8}$-nanocomposites with good electrochemical performance as anode material for aqueous rechargeable lithium batteries. J Power Sources 224:290-294. https://doi. org/10.1016/j.jpowsour.2012.09.100

Liu Y, Tang D, Zhong H, Zhang Q, Yang J, Zhang L (2016) Facile synthesis of nanostructured $\mathrm{Li}_{4} \mathrm{Ti}_{5} \mathrm{O}_{12}$ /PEDOT:PSS composite as anode material for lithium-ion batteries. RSC Adv 6:9551295517. https://doi.org/10.1039/C6RA20958K

Liu Y, Xie L, Zhang W, Dai Z, Wei W, Luo S, Chen X, Chen W, Rao F, Wang L, Huang Y (2019a) Conjugated system of PEDOT:PSSinduced self-doped PANI For Flexible Zinc-Ion Batteries With Enhanced Capacity And Cyclability. ACS Appl Mater Interfaces 11:30943-30952. https://doi.org/10.1021/acsami.9b09802

Liu J, Cheng M, Han T, Chen Y, Long J, Zeng X, Cheng L, Peng Z, Zhou P (2019c) A helix-shaped polyaniline/sulfur nanowire as novel structure-accommodable lithium-sulfur battery cathode for high-performance electrochemical lithium-storage. J Electroanal Chem 855:113543. https://doi.org/10.1016/j.jelec hem.2019.113543

Liu Y, Yan W, Zhang W, Kong W, Wang Z, Hao X, Guan G (2019b) 2D sandwich-like $\alpha$-zirconium phosphate/polypyrrole: moderate catalytic activity and true sulfur confinement for high-performance lithium-sulfur batteries. Chemsuschem 12:5172-5182. https:// doi.org/10.1002/cssc.201902227

Liu M, Wu X, Shen X, Luan K, Zhang Y, Yao S (2020d) Effects of nano- $\mathrm{TiO}_{2}$ particle size on microstructure and electrochemical performance of $\mathrm{TiO}_{2} / \mathrm{PEDOT}$ nanocomposites cathode in lithium-sulphur battery. Mater Technol. https://doi. org/10.1080/10667857.2020.1782310

Liu S, Zhu H, Zhang B, Li G, Zhu H, Ren H, Geng H, Yang Y, Liu Q, Li CC (2020e) Tuning the kinetics of zinc-ion insertion/extraction in $\mathrm{V}_{2} \mathrm{O}_{5}$ by in situ polyaniline intercalation enables improved aqueous zinc-ion storage performance. Adv Mater 32:2001113. https://doi.org/10.1002/adma.202001113

Liu Y, Pan Z, Tian D, Hu T, Jiang H, Yang J, Sun J, Zheng J, Meng C, Zhang Y (2020f) Employing "one for two" strategy to design polyaniline-intercalated hydrated vanadium oxide with expanded interlayer spacing for high-performance aqueous zinc-ion batteries. Chem Eng J 399:125842. https://doi.org/10.1016/j. cej.2020.125842

Liu X, Zai J, Iqbal A, Chen M, Ali N, Qi R, Qian X (2020a) Glycerol-crosslinked PEDOT:PSS as bifunctional binder for $\mathrm{Si}$ anodes: improved interfacial compatibility and conductivity. $\mathbf{J}$ Colloid Interface Sci 565:270-277. https://doi.org/10.1016/j. jcis.2020.01.028

Liu X, Xu G, Zhang Q, Huang S, Li L, Wei X, Cao J, Yang L, Chu PK (2020b) Ultrathin hybrid nanobelts of single-crystalline $\mathrm{VO}_{2}$ and Poly(3,4-ethylenedioxythiophene) as cathode materials for aqueous zinc ion batteries with large capacity and high-rate capability. J Power Sources 463:228223. https://doi.org/10.1016/j.jpows our.2020.228223

Liu X, Ma H, Xu H, Tan Z, Liu Q, Wang Y, Shu H, Wang D (2020c) Polypyrrole modified hierarchical porous CoS2@RGO aerogel electrode for ultrafast sodium storage. J Solid State Electr 24:8191. https://doi.org/10.1007/s10008-019-04462-8

Lu Q, Zhu Q, Guo W, Li X (2019) Polypyrrole-modified carbon nanotubes@manganese dioxide@sulfur composite for lithium-sulfur batteries. Ionics 25:3107-3119. https://doi.org/10.1007/s1158 1-019-02847-3

Lukyanov DA, Apraksin RV, Yankin AN, Vlasov PS, Levin OV, Tolstopjatova EG, Kondratiev VV (2019) Synthesis and electrochemical properties of Poly(3,4-dihydroxystyrene) and its composites with conducting polymers. Synth Metals 256:116151. https://doi.org/10.1016/j.synthmet.2019.116151 
Luo Y, Guo R, Li T, Li F, Liu Z, Zheng M, Wang B, Yang Z, Luo H, Wan Y (2019) Application of polyaniline for Li-ion batteries, lithium-sulfur batteries, and supercapacitors. Chemsuschem 12:1591-1611. https://doi.org/10.1002/cssc.201802186

Ma T, Zhao Q, Wang J, Pan Z, Chen J (2016) A sulfur heterocyclic quinone cathode and a multifunctional binder for a high-performance rechargeable lithium-ion battery. Angew Chem Int Ed 55:6428-6432. https://doi.org/10.1002/anie.201601119

Ma L, Wang X, Sun J (2020b) A strategy associated with conductive binder and 3D current collector for aqueous zinc-ion batteries with high mass loading. J Electroanal Chem 873:114395. https ://doi.org/10.1016/j.jelechem.2020.114395

Ma Y, Xu M, Zhang J, Liu R, Wang Y, Xiao H, Huang Y, Yuan G (2020a) Improving electrochemical performance of Ni-rich $\mathrm{LiNi}_{0.8} \mathrm{Co}_{0.1} \mathrm{Mn}_{0.1} \mathrm{O}_{2}$ cathode for Li-ion batteries by dualconductive coating layer of PPy and LiAlO2. J Alloys Compd 848:156387. https://doi.org/10.1016/j.jallcom.2020.156387

Mammone RJ (1987) In: Conducting Polymers - Special Applications. Alcacer L (ed), D. Reidel Publishing Company, Dordrecht, p. 161-172

Mao J, Wu FF, Shi WH, Liu WX, Xu XL, Cai GF, Li YW, Cao XH (2020) Preparation of polyaniline-coated composite aerogel of $\mathrm{MnO}_{2}$ and reduced graphene oxide for high-performance zinc-ion battery. Chin J Polym Sci 38:514-521. https://doi.org/10.1007/ s10118-020-2353-6

Martha SK, Hariprakash B, Gaffoor SA, Trivedi DC, Shukla AK (2006) A low-cost lead-acid battery with high specific-energy. J Chem Sci 118:93-98. https://doi.org/10.1007/BF02708770

Matsunaga T, Daifuku H, Kawagoe T (1990) Development of polyaniline lithium secondary battery. Nippon Kagaku Kaishi 1990:111. https://doi.org/10.1246/nikkashi.1990.1

Medvedev OS, Wang Q, Popovich AA, Novikov PA (2020) Comparison of conductive additives for high-power applications of Li-ion batteries. Ionics 26:4277-4286. https://doi.org/10.1007/s 1158 1-020-03631-4

Mu S (2004) Rechargeable batteries based on poly(aniline-co-o-aminophenol) and the protonation of the copolymer. Synth Metals 143:269-275. https://doi.org/10.1016/j.synthmet.2003.12.009

Mu K, Tao Y, Peng Z, Hu G, Du K, Cao Y (2019) Surface architecture modification of high capacity $\mathrm{Li}_{1.2} \mathrm{Ni}_{0.2} \mathrm{Mn}_{0.6} \mathrm{O}_{2}$ with synergistic conductive polymers LiPPA and PPy for lithium ion batteries. Appl Surf Sci 495:143503. https://doi.org/10.1016/j.apsus c.2019.07.245

Nakahara K, Iwasa S, Satoh M, Morioka Y, Iriyama J, Suguro M, Hasegawa E (2002) Rechargeable batteries with organic radical cathodes. Chem Phys Lett 359:351-354. https://doi.org/10.1016/ S0009-2614(02)00705-4

Nam Jo Y, Santhoshkumar P, Prasanna K, Vediappan K, Woo Lee C (2019) Improving self-discharge and anti-corrosion performance of $\mathrm{Zn}$-air batteries using conductive polymer-coated $\mathrm{Zn}$ active materials. J Ind Eng Chem 76:396-402. https://doi.org/10.1016/j. jiec.2019.04.005

Naoi K, Ueyama KI, Osaka T, Smyrl WH (1990) Impedance analysis of ionic transport in polypyrrole-polyazulene copolymer and its charge-discharge characteristics. J Electrochem Soc 137:494499. https://doi.org/10.1149/1.2086469

Nayana V, Kandasubramanian B (2020) Polycarbazole and its derivatives: progress, synthesis, and applications. J Polym Res 27:285. https://doi.org/10.1007/s10965-020-02254-7

Nishio K, Furukawa N (2011) Practical batteries. In: Daniel C, Besenhard JO (eds) Handbook of battery materials. Wiley-VCH, Weinheim, pp 62-62

Novak P, Müller K, Santhanam KSV, Haas O (1997) Electrochemically active polymers for rechargeable batteries. Chem Rev 97:207281. https://doi.org/10.1021/cr941181o
Nuanwat W, Pattananuwat P (2019) Preparation of polypyrrole coated zinc anode electrode for inhibition corrosion of secondary zinc ion battery. IOP Conf Ser Mater Sci Eng 600:012002. https://doi. org/10.1088/1757-899X/600/1/012002

Nueangnoraj K, Tomai T, Nishihara H, Kyotani T, Honma I (2016) An organic proton battery employing two redox-active quinones trapped within the nanochannels of zeolite-templated carbon. Carbon 107:831-836. https://doi.org/10.1016/j.carbo n.2016.06.096

Oka K, Strietzel C, Emanuelsson R, Nishide H, Oyaizu K, Strømme M, Sjödin M (2019) Characterization of PEDOT-Quinone conducting redox polymers in water-in-salt electrolytes for safe and high-energy Li-ion batteries. Electrochem Commun 105:106489. https://doi.org/10.1016/j.elecom.2019.106489

Otero TF, Cantero I (1999) Conducting polymers as positive electrodes in rechargeable lithium-ion batteries. J Power Sources 81-82:838-841. https://doi.org/10.1016/S0378-7753(98)00236-5

Oyaizu K, Nishide H (2009) Radical polymers for organic electronic devices: a radical departure from conjugated polymers? Adv Mater 21:2339-2344. https://doi.org/10.1002/adma.200803554

Ozerova VV, Stenina IA, Kuz'mina AA, Kulova TL, Yaroslavtsev AB (2020) Cathode materials based on lithium iron phosphate/ PEDOT composites for lithium-ion batteries. Inorg Mater 56:648-656. https://doi.org/10.1134/S0020168520050106

Park KS, Schougaard SB, Goodenough JB (2007) Conducting-polymer/iron-redox-couple composite cathodes for lithium secondary batteries. Adv Mater 19:848-851. https://doi.org/10.1002/ adma.200600369

Pavlov D (2006) Essentials of lead-acid batteries. In: Hariprakash B, Prem Kumar T, Shukla A-K (eds). SAEST, Karaikudi

Payami E, Aghaiepour A, Rahimpour K, Mohammadi R, TeimuriMofrad T (2020) Design and synthesis of ternary GO-Fc/ $\mathrm{Mn}_{3} \mathrm{O}_{4} / \mathrm{PANI}$ nanocomposite for energy storage applications. J Alloys Compd 829:154485. https://doi.org/10.1016/j.jallc om.2020.154485

Pirnat K, Dominko R, Cerc-Korosec R, Mali G, Genorio B, Gaberscek M (2012) Electrochemically stabilised quinone based electrode composites for Li-ion batteries. J Power Sources 199:308-314. https://doi.org/10.1016/j.jpowsour.2011.10.068

Pirnat K, Mali G, Gabrescek M, Dominko R (2016) Quinone-formaldehyde polymer as an active material in Li-ion batteries. J Power Sources 315:169-178. https://doi.org/10.1016/j.jpows our.2016.03.010

Qi S, Zhang X, Lv W, Zhang Y, Kong D, Huang Z, Yang QH (2019) Electrode design from "internal" to "external" for high stability silicon anodes in lithium-ion batteries. ACS Appl Mater Interfaces 11:14142-14149. https://doi.org/10.1021/acsami.9b02206

Qi Y, Nguyen MHT, Oh ES (2020) Enhancement of the lithium titanium oxide anode performance by the copolymerization of conductive polypyrrole with poly(acrylonitrile/butyl acrylate) binder. J Appl Electrochem 50:431-438. https://doi.org/10.1007/ s10800-020-01401-8

Qin X, Wang X, Sun J, Lu Q, Omar A, Mikhailova D (2020) Polypyrrole wrapped $\mathrm{V}_{2} \mathrm{O}_{5}$ nanowires composite for advanced aqueous zinc-ion batteries. Front Energy Res 8:199. https://doi. org/10.3389/fenrg.2020.00199

Rahmanifar MS, Mousavi MF, Shamsipur M (2002) Effect of selfdoped polyaniline on performance of secondary Zn-polyaniline battery. J Power Sources 110:229-232. https://doi.org/10.1016/ S0378-7753(02)00260-4

Raj H, Sil A (2019) PEDOT:PSS coating on pristine and carbon coated $\mathrm{LiFePO}_{4}$ by one-step process: the study of electrochemical performance. J Mater Sci Mater Electr 30:13604-13616. https://doi. org/10.1007/s10854-019-01730-1

Rajeev KK, Kim E, Nam J, Lee S, Mun J, Kim TH (2020) Chitosangrafted-polyaniline copolymer as an electrically conductive 
and mechanically stable binder for high-performance $\mathrm{Si}$ anodes in Li-ion batteries. Electrochim Acta 333:135532. https://doi. org/10.1016/j.electacta.2019.135532

Rajkumar P, Diwakar K, Gnanamuthu RM, Subadevi R, Sivakumar M (2019) Investigations on partially reduced graphene oxide capped sulfur/polyaniline composite as positive electrode material for lithium-sulfur battery. Mater Res Express 6:094005. https://doi. org/10.1088/2053-1591/ab2e59

Rasool M, Chiu HC, Zank B, Zeng Y, Zhou J, Zaghib K, Perepichka DF, Demopoulos GP (2020) PEDOT encapsulated and mechanochemically engineered silicate nanocrystals for high energy density cathodes. Adv Mater Interfaces 7:2000226. https://doi. org/10.1002/admi.202000226

Raulo A, Bandyopadhyay S, Ahamad S, Gupta A, Srivastava R, Formanek P, Nandan B (2019) Bio-inspired poly(3,4-ethylenedioxythiophene): poly(styrene sulfonate)-sulfur@polyacrylonitrile electrospun nanofibers for lithium-sulfur batteries. J Power Sources 431:250-258. https://doi.org/10.1016/j.jpows our.2019.05.055

Ren Y, Hu J, Zhong H, Zhang L (2020b) Multiple core-shelled sulfur composite based on spherical double-layered hollow carbon and PEDOT:PSS as cathode for lithium-sulfur batteries. J Alloys Compd 837:155498. https://doi.org/10.1016/j.jallc om.2020.155498

Ren X, Ai D, Lv R, Kang F, Huang ZH (2020a) Facile preparation of $\mathrm{V}_{2} \mathrm{O}_{5} / \mathrm{PEDOT}$ core-shell nanobelts with excellent lithium storage performance. Electrochim Acta 336:135723. https://doi. org/10.1016/j.electacta.2020.135723

Rousselot S, Antitomaso P, Savignac L, Généreux S, Taylor LW, Bibienne T, Pasquali M, Schougaard SB, Dollé M (2020) PEDOT assisted CNT self-supported electrodes for high energy and power density. Electrochim Acta 349:136418. https://doi. org/10.1016/j.electacta.2020.136418

Sanchez De Pinto MI, Mishima HT, López De Mishima BA (1997) Polymers and copolymers of pyrrole and thiophene as electrodes in lithium cells. J Appl Electrochem 27:831-838. https://doi. org/10.1023/a:1018476929590

Schoetz T, Craig B, Ponce de Leon C, Bund A, Ueda M, Low CTJ (2020) Aluminium-poly(3,4-ethylenedioxythiophene) rechargeable battery with ionic liquid electrolyte. J Energy Storage 28:101176. https://doi.org/10.1016/j.est.2019.101176

Shao M, Shang C, Zhang F, Xu Z, Hu W, Lu Q, Gai L (2021) Selective adsorption-involved formation of NMC532/PANI microparticles with high ageing resistance and improved electrochemical performance. J Energy Chem 54:668-679. https://doi.org/10.1016/j. jechem.2020.07.001

Sheng L, Fang D, Wang X, Tang J, Han Q, Zhou J, Tang W (2020) Boosting PEDOT energy storage with redox dopant and electrolyte additive. Chem Eng J 401:126123. https://doi.org/10.1016/j. cej.2020.126123

Shestakov AF, Litvinenko MA, Stevenson KJ (2018) Theoretical study of the structure and specific capacity of an organic cathode based on poly(2,5-diaza-1,4-benzoquinone) in a lithiated state. Mendeelev Commun 28:239-241. https://doi.org/10.1016/j.menco m.2018.05.003

Shi HY, Ye YJ, Liu K, Song Y, Sun X (2018) A long-cycle-life selfdoped polyaniline cathode for rechargeable aqueous zinc batteries. Angew Chem Int Ed 57:16359-16363. https://doi. org/10.1002/anie.201808886

Shi H, Qin J, Huang K, Lu P, Zhang C, Dong Y, Ye M, Liu Z, Wu ZS (2020) A two-dimensional mesoporous polypyrrole-graphene oxide heterostructure as a dual-functional ion redistributor for dendrite-free lithium metal anodes. Angew Chem Int Ed 59:12147-12153. https://doi.org/10.1002/anie.202004284
Shin WK, Yoo JH, Kim DW (2015) Surface-modified separators prepared with conductive polymer and aluminum fluoride for lithium-ion batteries. J Power Sources 279:737-744. https://doi. org/10.1016/j.jpowsour.2015.01.047

Song Z, Qian Y, Liu X, Zhang T, Zhu Y, Yu H, Otani M, Zhou H (2014) A quinone-based oligomeric lithium salt for superior Liorganic batteries. Energy Environ Sci 7:4077-4086. https://doi. org/10.1039/c4ee02575j

Song Z, Qian Y, Gordin ML, Tang D, Xu T, Otani M, Zhan H, Zhou $\mathrm{H}$, Wang D (2015) Polyanthraquinone as a reliable organic electrode for stable and fast lithium storage. Angew Chem Int Ed 54:13947-13951. https://doi.org/10.1002/anie.201506673

Song H, Pan Y, Tang A, Xu G, Liu L, Chen H (2019) Polypyrrolecoated loose network mesoporous carbon/sulfur composite for high-performance lithium-sulfur batteries. Ionics 25:3121-3127. https://doi.org/10.1007/s11581-019-02866-0

Song H, Yuan H, Chen H, Tang A, Xu G, Liu L, Zhang Z, Kuang Q (2020) Synthesis of $\mathrm{TiO}_{2} / \mathrm{S} @ \mathrm{PPy}$ composite for chemisorption of polysulfides in high performance Li-S batteries. J Solid State Electr 24:997-1006. https://doi.org/10.1007/s10008-020-04564 $-8$

Sotomura T, Uemachi H, Takeyama K, Naoi K, Oyama N (1992) New organodisulfide-polyaniline composite cathode for secondary lithium battery. Electrochim Acta 37:1851-1854. https://doi org/10.1016/0013-4686(92)85089-4

Stejskal J, Trchova M (2018) Conducting polypyrrole nanotubes: a review. Chem Pap 72:1563-1595. https://doi.org/10.1007/s1169 6-018-0394-x

Stejskal J, Sapurina I, Trchov M (2010) Polyaniline nanostructures and the role of aniline oligomers in their formation. Prog Polym Sci 35:1420-1481. https://doi.org/10.1016/j.progpolyms ci.2010.07.006

Sterby N, Emanuelsson R, Huang X, Gogoll A, Stromme M, Sjöding M (2017) Characterization of PEDOT-quinone conducting redox polymers for water based secondary batteries. Electrochim Acta 235:356-364. https://doi.org/10.1016/j.electacta.2017.03.068

Strekalova SO, Shekurov RP, Gilmanova LH, Gerasimova TP, Grinenko VV, Kononov AI, Dolengovski EL, Budnikova YH, Khrizanforov MN (2019) Ferrocene-containing coordination polymers as way for preparation of energy carriers. Phosphorus Sulfur Silicon Relat Elem 194:571-574. https://doi. org/10.1080/10426507.2018.1543302

Su C, Wang L, Xu L, Liu J, Yang F, Zhang C (2012) Syntheses and properties of pyrrole derivative as a cathode material for $\mathrm{Li}$ ion batteries. Appl Mech Mater 236-237:731-735. https://doi. org/10.4028/www.scientific.net/AMM.236-237.731

Su C, Wang L, Xu L, Zhang C (2013) Synthesis of a novel ferrocenecontained polypyrrole derivative and its performance as a cathode material for Li-ion batteries. Electrochim Acta 104:302-307. https://doi.org/10.1016/j.electacta.2013.04.127

Su C, Ji L, Xu L, Zhu X, He H, Lv Y, Ouyang M, Zhang C (2015) A novel ferrocene-containing aniline copolymer: Its synthesis and electrochemical performance. RSC Adv 5:14053-14060. https:// doi.org/10.1039/c4ra12476f

Su C, Guo P, Xu L (2020) Preparation of Li (tri-(4-carboxyphenyl) amine) doped polypyrrole as cathode material of lithium ion batteries and its electrochemical performances. Solid State Ion 349:115295. https://doi.org/10.1016/j.ssi.2020.115295

Suga T, Sugita S, Ohshiro H, Oyaizu K, Nishide H (2011) P- and n-type bipolar redox-active radical polymer: toward totally organic polymer-based rechargeable devices with variable configuration. Adv Mater 23:751-754. https://doi.org/10.1002/adma.201003525

Sui Y, Liu C, Zou P, Zhan H, Cui Y, Yang C, Cao G (2020) Polypyrrole coated $\delta-\mathrm{MnO}_{2}$ nanosheet arrays as a highly stable 
lithium-ion-storage anode. Dalton Trans 49:7903-7913. https:// doi.org/10.1039/d0dt01658f

Sun X, Zhang Y, Zhang J, Zaman FU, Hou L, Yuan C (2020) Bi-metal ( $\mathrm{Zn}, \mathrm{Mn}$ ) metal-organic framework-derived $\mathrm{ZnMnO}_{3}$ microsheets wrapped uniformly with polypyrrole conductive network toward high-performance li-ion batteries. Energy Technol 8:1901218. https://doi.org/10.1002/ente.201901218

Syrový T, Kazda T, Syrová L, Vondrák J, Kubáč L, Sedlaříková M (2016) Cathode material for lithium ion accumulators prepared by screen printing for Smart Textile applications. J Power Sources 309:192-201. https://doi.org/10.1016/j.jpows our.2016.01.089

Takada K, Gopalan P, Ober CK, Abruna HD (2001) Synthesis, characterization, and redox reactivity of novel quinone-containing polymer. Chem Mater 13:2928-2932. https://doi.org/10.1021/ $\mathrm{cm} 010159 \mathrm{q}$

Tang H, You L, Liu J, Wang S, Wang P, Feng C, Guo C (2019) Integrated Polypyrrole@Sulfur@Graphene aerogel 3D architecture via advanced vapor polymerization for high-performance lithium-sulfur batteries. ACS Appl Mater Interfaces 11:1844818455. https://doi.org/10.1021/acsami.9b04167

Tong J, Han C, Hao X, Qin X, Li B (2020) Conductive polyacrylic acid-polyaniline as a multifunctional binder for stable organic quinone electrodes of lithium-ion batteries. ACS Appl Mater Interfaces 12:39630-39638. https://doi.org/10.1021/acsam i.0c10347

Vetter KJ (1967) Electrochemical kinetics. Theoretical and experimental aspects. Academic Press, New York

Volkov AI, Eliseeva SN, Tolstopjatova EG, Kondratiev VV (2020) Enhanced electrochemical performance of $\mathrm{MoS}_{2}$ anode material with novel composite binder. J Solid State Electrochem 24:16071614. https://doi.org/10.1007/s10008-020-04701-3

Walker W, Grugeon S, Vezin H, Laruelle S, Armand M, Tarascon JM, Wudl F (2010) The effect of length and cis/trans relationship of conjugated pathway on secondary battery performance in organolithium electrodes. Electrochem Commun 12:1348-1351. https://doi.org/10.1016/j.elecom.2010.07.017

Wang J, Zhang S (2020) Synthesis of polyaniline-sulfur composites with different nanostructures: via an interfacial emulsification method and a micelle template method and their properties. RSC Adv 10:11455-11462. https://doi.org/10.1039/d0ra00122h

Wang D, Erten-Ela S, Zakeeruddin SM, Pechy P, Exnar I, Wang Q, Grätzel M (2009) Polymer wiring of insulating electrode materials: an approach to improve energy density of lithium-ion batteries. Electrochem Commun 11:1350-1352. https://doi. org/10.1016/j.elecom.2009.04.030

Wang X, Shen L, Li H, Wang J, Dou H, Zhang X (2014) PEDOT coated $\mathrm{Li}_{4} \mathrm{Ti}_{5} \mathrm{O}_{12}$ nanorods: soft chemistry approach synthesis and their lithium storage properties. Electrochim Acta 129:283289. https://doi.org/10.1016/j.electacta.2014.02.112

Wang P, Chen Z, Ji Z, Feng Y, Wang J, Liu J, Hu M, Wang H, Gan W, Huang Y (2019e) A flexible aqueous Al ion rechargeable full battery. Chem Eng J 373:80-586. https://doi.org/10.1016/j. cej.2019.05.085

Wang X, Zhang Y, Shi Y, Zeng X, Tang R, Wei L (2019f) Conducting polyaniline/poly (acrylic acid)/phytic acid multifunctional binders for $\mathrm{Si}$ anodes in lithium ion batteries. Ionics 25:5323-5331. https://doi.org/10.1007/s11581-019-03122-1

Wang Z, Han JJ, Zhang N, Sun DD, Han T (2019g) Synthesis of polyaniline/graphene composite and its application in zinc-rechargeable batteries. J Solid State Electrochem 23:3373-3382. https:// doi.org/10.1007/s10008-019-04435-x

Wang G, Bi X, Yue H, Jin R, Wang Q, Gao S, Lu J (2019d) Sacrificial template synthesis of hollow C@ $\mathrm{MoS}_{2} @ \mathrm{PPy}$ nanocomposites as anodes for enhanced sodium storage performance. Nano Energy 60:362-370. https://doi.org/10.1016/j.nanoen.2019.03.065
Wang X, Zhang S, Zhang H, Gao S, Han S, Xu Q, Xu J, Lu W, Wu X, Chen L (2019a) 3D porous spherical sulfur/carbon cathode materials with in situ vapor-phase polymerized polypyrrole coating layer for high-performance lithium-sulfur batteries. ACS Sustain Chem Eng 7:17491-17499. https://doi.org/10.1021/acssuschem eng.9b04805

Wang M, Wang X, Yao Z, Tang W, Xia X, Gu C, Tu J (2019b) $\mathrm{SnO}_{2}$ nanoflake arrays coated with polypyrrole on a carbon cloth as flexible anodes for sodium-ion batteries. ACS Appl Mater Interfaces 11:24198-24204. https://doi.org/10.1021/acsami.9b08378

Wang K, Huang SP, Wu Y, Cai NN, Li N, Xiao Q, Sun Z (2019c) Critical thickness of a surface-functionalized coating for enhanced lithium storage: a case study of nanoscale polypyrrole-coated $\mathrm{FeS}_{2}$ as a cathode for Li-ion batteries. Nanoscale 11:1627716283. https://doi.org/10.1039/c9nr05523a

Wang D, Hong X, Liu S, Ge X, Tang B, Wang H, Xie K, Ren W (2020d) Reversible insertion/extraction of polysulfides into/from polyaniline as an effective strategy to confine polysulfides in lithium-sulfur batteries. Ionics 26:191-199. https://doi.org/10.1007/ s11581-019-03209-9

Wang J, Gao L, Gu C, Wang J, Huang J (2020e) Polypyrrole-coated hollow zeolite microcake as sulfur host for lithium-sulfur batteries with improved electrochemical behaviors. J Electroanal Chem 877:114565. https://doi.org/10.1016/j.jelechem.2020.114565

Wang Y, Jiang H, Zheng R, Pan J, Niu J, Zou X, Jia C (2020f) A flexible, electrochromic, rechargeable Zn-ion battery based on actiniae-like self-doped polyaniline cathode. J Mater Chem A 8:12799-12809. https://doi.org/10.1039/d0ta04203j

Wang X, Wang B, Tang Y, Xu BB, Liang C, Yan M, Jiang Y (2020c) Manganese hexacyanoferrate reinforced by PEDOT coating towards high-rate and long-life sodium-ion battery cathode. J Mater Chem A 8:3222-3227. https://doi.org/10.1039/c9ta1 $2376 \mathrm{~h}$

Wang S, Huang S, Yao M, Zhang Y, Niu Z (2020a) Engineering active sites of polyaniline for storage in an aluminum-ion battery. Angew Chem Int Ed 59:11800-11807. https://doi.org/10.1002/ anie. 202002132

Wang D, Hu H, Liao Y, Kong D, Cai T, Gao X, Hu H, Wu M, Xue Q, Yan Z, Ren H, Xing W (2020b) High-performance aluminumpolyaniline battery based on the interaction between aluminum ion and -NH groups. Sci China Mater. https://doi.org/10.1007/ s40843-020-1398-5

Wei Y, Yan Y, Zou Y, Shi M, Deng Q, Zhao N, Wang J, Yang R, Xu Y (2019c) The ternary PANI@BDC/S composite cathode with enhanced electrochemical performance in lithium-sulfur batteries. J Electroanal Chem 839:149-159. https://doi.org/10.1016/j. jelechem.2019.03.014

Wei Y, Yan Y, Zou Y, Shi M, Deng Q, Zhao N, Wang J, You C, Yang $\mathrm{R}, \mathrm{Xu}$ Y (2019b) Sulfonated polyaniline coated bamboo-derived biochar/sulfur cathode for Li-S batteries with excellent dual conductivity and polysulfides affinity. Electrochim Acta 310:45-57. https://doi.org/10.1016/j.electacta.2019.04.067

Wei M, Wang Y, Li C, Jin C, Sui J, Yang R (2019a) PPy-derived sandwich-structured hollow carbon fiber anchoring $\mathrm{Sn}_{4} \mathrm{P}_{3}$ as anode materials with improved $\mathrm{Na}^{+}$storage. ChemNanoMat 5:14711476. https://doi.org/10.1002/cnma.201900445

Wei W, Li J, Wang Q, Liu D, Niu J, Liu P (2020b) Hierarchically porous $\mathrm{SnO}_{2}$ nanoparticle-anchored polypyrrole nanotubes as a high-efficient sulfur/polysulfide trap for high-performance lithium-sulfur batteries. ACS Appl Mater Interfaces 12:6362-6370. https://doi.org/10.1021/acsami.9b18426

Wei W, Li J, Liu D, Pan C, Liu P (2020a) Well-defined hierarchically porous double-shell hollow polypyrrole@sulfur microspheres with outer sulfur shells for lithium-sulfur batteries with superior electrochemical performance. Energy Fuels 34:7676-7683. https ://doi.org/10.1021/acs.energyfuels.0c01163 
Wei W, Li J, Wang Q, Liu D, Niu J, Liu P (2020c) Uniform polypyrrole layer-coated sulfur/graphene aerogel via the vapor-phase deposition technique as the cathode material for $\mathrm{Li}-\mathrm{S}$ batteries. ACS Appl Mater Interfaces 12:6362-6370. https://doi.org/10.1021/ acsami.9b20426

Wu J, Li S, Yang P, Zhang H, Du C, Xu J, Song K (2019) S@ $\mathrm{TiO}_{2}$ nanospheres loaded on PPy matrix for enhanced lithium-sulfur batteries. J Alloy Compd 783:279-285. https://doi.org/10.1016/j. jallcom.2018.12.316

Wu T, Sun G, Lu W, Zhao L, Mauger A, Julien CM, Sun L, Xie H, Liu $\mathrm{J}$ (2020c) A polypyrrole/black- $\mathrm{TiO}_{2} / \mathrm{S}$ double-shelled composite fixing polysulfides for lithium-sulfur batteries. Electrochim Acta 353:136529. https://doi.org/10.1016/j.electacta.2020.136529

Wu J, Dai Y, Pan Z, Huo D, Wang T, Zhang H, Hu J, Yan S (2020b) $\mathrm{Co}_{3} \mathrm{O}_{4}$ hollow microspheres on polypyrrole nanotubes network enabling long-term cyclability sulfur cathode. Appl Surf Sci 510:145529. https://doi.org/10.1016/j.apsusc.2020.145529

Wu W, Kang Y, Wang M, Xu D, Wang J, Cao J, Wang C, Deng Y (2020a) An ultrahigh-areal-capacity $\mathrm{SiO}_{\mathrm{x}}$ negative electrode for lithium ion batteries. J Power Sources 464:228244. https://doi. org/10.1016/j.jpowsour.2020.228244

Xu L, Ji L, Wang G, Zhang C, Su C (2016) A novel nitroxide radical polymer-containing conductive polyaniline as molecular skeleton: its synthesis and electrochemical properties as organic cathode. Ionics 22:1377-1385. https://doi.org/10.1007/s1158 1-016-1663-8

Xu L, Guo P, He H, Zhou N, Ma J, Wang G, Zhang C, Su C (2017) Preparation of TEMPO-contained pyrrole copolymer by in situ electrochemical polymerization and its electrochemical performances as cathode of lithium ion batteries. Ionics 23:1375-1382. https://doi.org/10.1007/s11581-016-1965-x

Xu Z, Zhang Z, Li M, Yin H, Lin H, Zhou J, Zhuo S (2019) Threedimensional $\mathrm{ZnS} /$ reduced graphene oxide/polypyrrole composite for high-performance supercapacitors and lithium-ion battery electrode material. J Solid State Electrochem 23:3419-3428. https://doi.org/10.1007/s10008-019-04434-y

Xue X, Zhang H, Yuan S, Shi L, Zhao Y, Wang Z, Chen H, Zhu J (2020) PEDOT:PSS @ molecular sieve as dual-functional additive to enhance electrochemical performance and stability of Ni-rich NMC lithium-ion batteries. Energy Technol 8:2000339. https://doi.org/10.1002/ente.202000339

Yang L, Huang X, Gogoll A, Strømme M, Sjödin M (2016) Conducting redox polymer based anode materials for high power electrical energy storage. Electrochim Acta 204:270-275. https://doi. org/10.1016/j.electacta.2016.03.163

Yang L, Wu W, Ohki Y, Feng Y, Li S (2017) Enhanced conductivity of polyaniline in the presence of nonionic amphiphilic polymers and their diverse morphologies. J Appl Polym Sci 134:45547. https://doi.org/10.1002/app.45547

Yang X, Liu X, Qin T, Zhang X, Zhang W, Zheng W (2020b) Polypyrrole coated hollow $\mathrm{S} / \mathrm{Co}$-doped carbon nanocages excels for packaging high-performance lithium sulfur batteries. Nanotechnology 31:275404. https://doi.org/10.1088/1361-6528/ab849f

Yang X, Wu H, Feng C (2020a) Synthesis and electrochemical performance of $\mathrm{Sb}_{2} \mathrm{WO}_{6} @ \mathrm{PPy}$ as novel anode material for lithium ion battery application. J Mater Sci Mater Electron 31:4761-4768. https://doi.org/10.1007/s10854-020-03033-2

Yao Y, Zhang H, Wang X (2019b) Polyaniline: an effective suppressor against diffusion and dissolution of polysulfides in $\mathrm{Li}-\mathrm{S}$ battery. $\mathrm{J}$ Solid State Electrochem 23:2559-2567. https://doi.org/10.1007/ s10008-019-04340-3

Yao CJ, Xie J, Wu Z, Xu ZJ, Zhang S, Zhang Q (2019a) A conjugated copolymer of $N$-Phenyl-p-phenylenediamine and pyrene as promising cathode for rechargeable lithium-ion batteries. Chem Asian J 14:2210-2214. https://doi.org/10.1002/asia.201900520
Yao H, Li Q, Zhang M, Tao Z, Yang Y (2020) Prolonging the cycle life of zinc-ion battery by introduction of $\left[\mathrm{Fe}(\mathrm{CN})_{6}\right]^{4-}$ to PANI via a simple and scalable synthetic method. Chem Eng J 392:123653. https://doi.org/10.1016/j.cej.2019.123653

Yi R, Lin X, Zhao Y, Liu C, Li Y, Hardwick LJ, Yang L, Zhao C, Geng X, Zhang Q (2019) Fabrication of a light-weight dual-function modified separator towards high-performance lithium-sulfur batteries. ChemElectroChem 6:3648-3656. https://doi.org/10.1002/ celc. 201900670

Yoo GW, Jang BC, Kim C, Son JT (2017) The effect of surface coating on $\mathrm{LiNi}_{0.6} \mathrm{Co}_{0.1} \mathrm{Mn}_{0.3} \mathrm{O}_{2}$ cathode material for lithium secondary battery by PEDOT-PEG block copolymer. Sci Adv Mater 9:790-794. https://doi.org/10.1166/sam.2017.2573

Zeng S, Li L, Zhao D, Liu J, Niu W, Wang N, Chen S (2017) Polymercapped sulfur copolymers as lithium-sulfur battery cathode: enhanced performance by combined contributions of physical and chemical confinements. J Phys Chem C 121:2495-2503. https://doi.org/10.1021/acs.jpcc.6b09543

Zeng Q, Wu J, Yu Z, Luo L (2018) Conductive PEDOT-decorated $\mathrm{Li}_{4} \mathrm{Ti}_{5} \mathrm{O}_{12}$ as next-generation anode material for electrochemical lithium storage. Solid State Ion 325:7-11. https://doi. org/10.1016/j.ssi.2018.07.023

Zhang F, Xiong P, Guo X, Zhang J, Yang W, Wu W, Liu H, Wang G (2019c) A nitrogen, sulphur dual-doped hierarchical porous carbon with interconnected conductive polyaniline coating for high-performance sodium-selenium batteries. Energy Storage Mater 19:251-260. https://doi.org/10.1016/j.ensm.2019.03.019

Zhang Y, Wang Q, Bi S, Yao M, Wan F, Niu Z (2019b) Flexible all-inone zinc-ion batteries. Nanoscale 11:17630-17636. https://doi. org/10.1039/c9nr06476a

Zhang M, Lu R, Yuan H, Amin K, Mao L, Yan W, Wei Z (2019a) Nanowire array-coated flexible substrate to accommodate lithium plating for stable lithium-metal anodes and flexible lithiumorganic batteries. ACS Appl Mater Interfaces 11:20873-20880. https://doi.org/10.1021/acsami.9b05056

Zhang P, Liu J, Zhou C, Guo S, Li S, Yang Y, Wu J, Yu D, Chen H, Zhao M, Chen L (2020d) Polypyrrole-derived nitrogen-doped carbon coated hierarchical $\mathrm{MnO}$ porous microspheres for highly reversible lithium storage. J Electroanal Chem 856:113733. https ://doi.org/10.1016/j.jelechem.2019.113733

Zhang Y, Xiao R, Liao X, Ma Z, Huang Y, Li Q (2020e) Polyaniline/ copper composite anode current collectors prepared through electrochemical polymerization for lithium-ion batteries. ChemElectroChem 7:2896-2904. https://doi.org/10.1002/celc.202000692

Zhang F, Wang C, Pan J, Tian F, Zeng S, Yang J, Qian Y (2020f) Polypyrrole-controlled plating/stripping for advanced zinc metal anodes. Mater Today Energy 17:100443. https://doi. org/10.1016/j.mtener.2020.100443

Zhang S, Long S, Li H, Xu Q (2020a) A high-capacity organic cathode based on active $\mathrm{N}$ atoms for aqueous zinc-ion batteries. Chem Eng J 400:125898. https://doi.org/10.1016/j.cej.2020.125898

Zhang P, Liu J, Wu J, Wang W, Zhou C, Guo S, Li S, Yang Y, Chen L (2020b) Self-assembly formation of hierarchical mixed spinel $\mathrm{MnCo}_{2} \mathrm{O}_{4}$ porous nanospheres confined by polypyrrole pyrolytic carbon for high-performance lithium storage. Mater Today Energy 17:100451. https://doi.org/10.1016/j.mtener.2020.100451

Zhang Y, Xu G, Liu X, Wei X, Cao J, Yang L (2020c) Scalable in situ reactive assembly of polypyrrole-coated $\mathrm{MnO}_{2}$ nanowire and carbon nanotube composite as freestanding cathodes for high performance aqueous $\mathrm{Zn}$-ion batteries. ChemElectroChem 7:2762-2770. https://doi.org/10.1002/celc.202000253

Zhao R, Zhu L, Cao Y, Ai X, Yang HX (2012) An aniline-nitroaniline copolymer as a high capacity cathode for Na-ion batteries. Electrochem Commun 21:36-38. https://doi.org/10.1016/j.eleco m.2012.05.015 
Zhao L, Wang W, Wang A, Yuan K, Chen S, Yang Y (2013) A novel polyquinone cathode material for rechargeable lithium batteries. J Power Sources 233:23-27. https://doi.org/10.1016/j.jpows our.2013.01.103

Zhao H, Wei Y, Qiao R, Zhu C, Zheng Z, Ling M, Jia Z, Bai Y, Fu Y, Lei J, Song X, Battaglia VS, Yang W, Messersmith PB, Liu G (2015) Conductive polymer binder for high-tap-density nanosilicon material for lithium-ion battery negative electrode application. Nano Lett 15:7927-7932. https://doi.org/10.1021/acs.nanol ett. 5 b03003

Zhao J, Yang J, Sun P, Xu Y (2018) Sodium sulfonate groups substituted anthraquinone as an organic cathode for potassium batteries. Electrochem Commun 86:34-37. https://doi.org/10.1016/j. elecom.2017.11.009

Zhao Y, Wang D, Li X, Yang Q, Guo Y, Mo F, Li Q, Peng C, Li H, Zhi $\mathrm{C}$ (2020) Initiating a reversible aqueous $\mathrm{Zn} / \mathrm{sulfur}$ battery through a "liquid film." Adv Mater 32:2003070. https://doi.org/10.1002/ adma.202003070

Zheng M, Wang C, Xu Y, Li K, Liu D (2019) A water-soluble binary conductive binder for Si anode lithium ion battery. Electrochim Acta 305:555-562. https://doi.org/10.1016/j.elect acta.2019.02.080

Zhou W, Xu J (2017) Progress in conjugated polyindoles: synthesis, polymerization mechanisms, properties, and applications. Polym
Rev 57:248-275. https://doi.org/10.1080/15583724.2016.12231 30

Zhou Y, Jin X, Ni J, Zhang S, Yang J, Liu P, Wang Z, Lei J (2019) Evaporation induced uniform polypyrrole coating on $\mathrm{CuO}$ arrays for free-standing high lithium storage anode. J Solid State Electrochem 23:1829-1836. https://doi.org/10.1007/s10008-01904285-7

Zhu L, Xie L, Bao C, Yan X, Cao X (2020) $\mathrm{LiNi}_{1 / 3} \mathrm{Co}_{1 / 3} \mathrm{Mn}_{1 / 3} \mathrm{O}_{2} /$ polypyrrole composites as cathode materials for high-performance lithium-ion batteries. Int J Energy Res 44:298-308. https ://doi.org/10.1002/er.4916

Zou Q, Wang W, Wang A, Yu Z, Yuan K (2014) Preparation of the tetrahydro-hexaquinone as a novel cathode material for rechargeable lithium batteries. Mater Lett 117:290-293. https://doi. org/10.1016/j.matlet.2013.12.027

Publisher's Note Springer Nature remains neutral with regard to jurisdictional claims in published maps and institutional affiliations. 